NBER WORKING PAPER SERIES

\title{
BARGAINING OVER TAXES AND ENTITLEMENTS
}

\author{
Marina Azzimonti \\ Gabriel P. Mihalache \\ Laura Karpuska \\ Working Paper 27595 \\ http://www.nber.org/papers/w27595 \\ NATIONAL BUREAU OF ECONOMIC RESEARCH \\ 1050 Massachusetts Avenue \\ Cambridge, MA 02138 \\ July 2020, Revised December 2020
}

We would like to thank Renee Bowen, Sandro Brusco, Juan Carlos Conesa, Ying Chen, Wiola Dziuda, Hulya Eraslan, Marcos Fernandes, Tasos Kalandrakis, Narayana Kocherlakota, Facundo Piguillem, and Jan Zapal for useful comments, as well as participants of the 2020 Political Economy meeting at the Stanford Institute for Theoretical Economics, the 83rd Midwest Economic Association Annual Meeting (St. Louis, Missouri), the 45th Eastern Economic Association, the 2020 RIDGE/LACEA-PEGWorkshop on Political Economy, INSPER, and the Wallis Institute.The views expressed herein are those of the authors and do not necessarily reflect the views of the National Bureau of Economic Research.

NBER working papers are circulated for discussion and comment purposes. They have not been peerreviewed or been subject to the review by the NBER Board of Directors that accompanies official NBER publications.

(C) 2020 by Marina Azzimonti, Gabriel P. Mihalache, and Laura Karpuska. All rights reserved. Short sections of text, not to exceed two paragraphs, may be quoted without explicit permission provided that full credit, including $(\mathcal{C}$ notice, is given to the source. 
Bargaining over Taxes and Entitlements

Marina Azzimonti, Gabriel P. Mihalache, and Laura Karpuska

NBER Working Paper No. 27595

July 2020, Revised December 2020

JEL No. C7,D6,E6,E62,H53

\begin{abstract}
We analyze the welfare implications of introducing budget rules, composed by a tax code and an entitlement program, in a dynamic infinite horizon political-economy model featuring disagreement over the distribution of resources. Poor agents want expansive entitlement programs, whereas rich agents prefer a small government that imposes low taxes. Under budget rules, changes in the tax code and the generosity of entitlement programs require bipartisan support. We model these rules following the literature on legislative bargaining with endogenous status quo, and find that entitlement programs induce under-provision of public goods but also a smoother path for private consumption. Whether budget rules are welfareimproving depends critically on political turnover. When proposers alternate frequently, such rules benefit society because they reduce the volatility of private consumption. Outcomes under rules, however, can be worse than under discretion if the political power of a proposer is persistent enough. Even though the political equilibrium may be more efficient in such case, it can also be significantly less equitable, exacerbating the initial degree of income inequality. We also consider an institutional reform, where parties are allowed to vote on both, the introduction and generosity of the entitlement program and the tax code. Because such a reform must be Pareto improving (by design), policymakers may prefer to stay under discretion.

Marina Azzimonti

Economics Department

Stony Brook University

100 Nicolls Road

Stony Brook, NY 11794

and NBER

marina.azzimonti@gmail.com

Gabriel P. Mihalache

S633, Social and Behavioral Sciences Bld.

Department of Economics

Stony Brook University

Stony Brook, NY 11794

USA

gabriel.mihalache@stonybrook.edu

Laura Karpuska

Sao Paulo School of Economics - FGV.

R Itapeva 474, Sao Paulo, SP

01332-000

Sao Paulo - SP

Brazil

laukarpuska@gmail.com
\end{abstract}




\section{Introduction}

Prior to the Great Depression, nearly all federal expenditures in the United States were discretionary. That is, spending did not occur in a given year unless Congress provided funding through an annual appropriations' bill. Following the Social Security Act of 1935, an increasing percentage of the federal budget became devoted to financing mandatory spending programs. Today, they represent over $60 \%$ of all government spending, as shown in the left panel of Figure 1 . Their key characteristic is that they need to be established under authorization laws and can only be changed with approval form a majority (or super-majority) of members of Congress. This results in a bargaining process similar to the one used when trying to modify the tax code.

While there is a wide range of goods financed by the government which are mandatory, the largest ones are entitlement programs such as Social Security, Medicaid, Income Security, and Medicare (see right panel of Figure 1), which provide private transfers to qualified individuals. These social welfare programs have specific criteria set by Congress, such as eligibility and benefit generosity, which generate significant redistribution towards eligible recipients from wealthier individuals. In this paper, we analyze the welfare implications of introducing 'budget rules,' composed by a tax code and entitlement programs, in a dynamic infinite horizon political-economy model featuring disagreement over the distribution of resources.
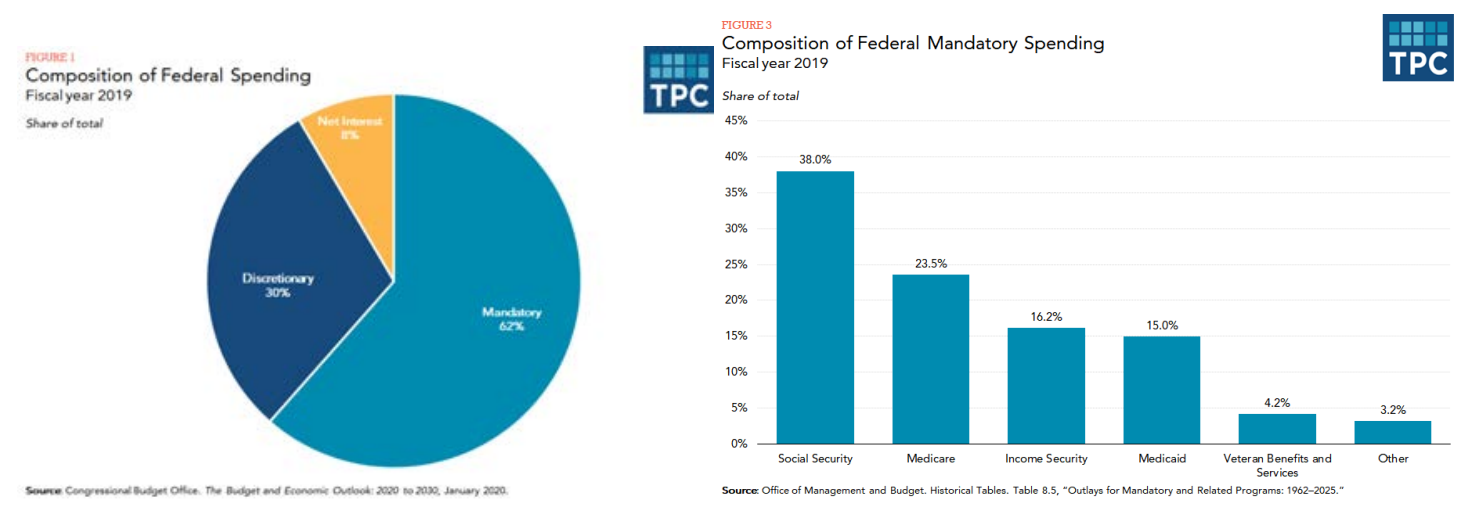

Figure 1: Composition of Federal Spending (left) and of Mandatory Spending (right), 2019

We study an endowment economy where two parties representing individuals from different income groups (rich and poor) must decide how to finance (pure) public goods and whether to redistribute resources through entitlement programs. While both agents have the same preferences, they disagree on the degree of redistribution. This is the case because rich agents are initially endowed with more resources than poor ones. As a result, the rich prefer a small government whose main role is to provide public goods, whereas the poor would like the government to provide generous entitlement programs - even if this involves high taxes. We do not restrict the set of instruments that policymakers have access to, so in principle the political equilibrium can be efficient. Our main friction, thus, is not distortionary taxation, but instead disagreement regarding where in the Pareto frontier society should be. Under the 'veil of ignorance' all agents agree on policies that decentralize the first best, which is both efficient and equitable. However, once they learn their type - at birth - each group prefers less equitable allocations that benefit them disproportionately. Political parties channel this through policy choices once they gain decision-making power. Their ability to do so depends on the institutional features regulating how fiscal policy is determined.

As a benchmark, we first characterize allocations where all spending is discretionary and 
taxes are residually determined. Under this institutional arrangement, parties alternate in power stochastically and changes in policy do not need consensus. Our analysis points to two sources of inefficiency arising in this case. Statically, the policymaker under-provides public goods relative to the efficient solution. Dynamically, the equilibrium under discretionary spending exhibits volatility of fiscal policy and consumption: a rich proposer tries to slash entitlement programs and introduce tax-cuts when in power, whereas a poor one tries to raise taxes and expand entitlements. This results in cyclical fiscal policy, which is sub-optimal: with a constant total endowment, efficient allocations are time-invariant. We note that while the resulting allocations are inefficient, they can exhibit a high degree of equity. When the initial endowment is one with large income inequality, power alternation may generate welfare gains under discretion-evaluated from an ex-ante perspective by a utilitarian planner-.

We then consider a political equilibrium with budget rules, that better resembles the current decision-making process for fiscal policy in the US. In this environment, changing the tax code and the generosity of the entitlement program requires bipartisan support. We follow the protocol used in the bargaining literature under endogenous status quo to represent policy determination (see, for example, Bowen, Chen, and Eraslan (2014)). Every period, a party is selected at random to make a budget proposal involving public good spending, entitlement provision, and taxes. The proposer makes a take-it-or-leave-it offer to the opposition. The proposal is only implemented if the other party accepts. If the proposal is rejected, a status-quo allocation (e.g. determined by the previously established tax code and entitlement program regulations) is implemented instead.

We show that budget rules make fiscal policy more persistent, reducing the inefficiently large volatility of discretionary policy. This is beneficial for welfare. In addition, these rules provide insurance against expropriation. By choosing the level of entitlements appropriately when in power, poor agents ensure a minimum degree of consumption through redistributive policies. By choosing taxes appropriately, rich agents ensure themselves against excessively high taxes. In the long-run, however, budget rules result in allocations involving too much private consumption and even less public good provision than discretion. Because of this, introducing budget rules may not generate a Pareto improvement. Interestingly, long-run allocations will typically be less equitable than those arising in a model without rules. The degree of inequity increases with political persistence. That is, if the current incumbent is significantly more likely to retain proposal power than the opposition, she can slowly tilt the system in her advantage. Because the status-quo is difficult to change, by being in power long enough, a given party can position itself in an advantageous bargaining position. This requires, however, sacrificing the common good through either too little taxation (by rich incumbents) or too large welfare programs (by poor incumbents).

The previous analysis makes it clear that a proposer would always have incentives to introduce budget rules in this environment because of the advantage associated with securing greater consumption of private goods for her constituents. The opposition party, on the other hand, may be worse off when the rules are introduced as the initial state of the political economy may favor the proposer. This raises the question of whether the opposition would agree to such institutional reform. To study this scenario, we also consider a "reform stage" where parties must agree on whether to introduce the budget rules. This one-time bargaining process must result (by design) in allocations that weakly increase the level of welfare attained by both parties. We show that political turnover is an important determinant of the welfare gains associated with the introduction of budget rules. Introducing a tax code and an entitlement program generates a Pareto improvement when political turnover is high (e.g. incumbency advantage is low). With enough persistence in power, on the other hand, these rules cannot improve over discretion.

Our paper makes three important contributions to the existing literature. First, we analyze the bargaining process over entitlement programs and taxes in an infinite horizon model with 
concave utilities. This allows us to evaluate the consequences of introducing budget rules in an environment where agents are heterogeneous in income levels and have preferences for smooth consumption profiles. A key finding is that introducing budget rules is not always beneficial to society. This is in contrast with Bowen, Chen, and Eraslan (2014), who find that efficient allocations can be attained when mandatory spending programs are introduced. Our results differ from theirs because they consider rules on public good provision, whereas we focus on rules affecting the determination of entitlement programs and taxes which directly affect private consumption. Our second contribution, thus, is to point out that the type of fiscal policy targeted by a budget rule matters. This feature of institutional design has been overlooked by most of the literature on dynamic bargaining. Our third contribution is methodological. Because we relax the linearity assumption on preferences used in most of the endogenous status-quo literature, characterization of the symmetric Markov-perfect equilibrium in the infinite-horizon dynamic game requires a numerical approach. We propose a numerical method that can robustly compute the equilibrium for a wide range of parameters. Computation is complex, because we have a multidimensional state space (e.g. two endogenous status-quo variables). Our method is inspired by Duggan and Kalandrakis (2012), and uses advances in the quantitative macroeconomics literature, such as those in Gordon (2019).

A brief literature review can be found in the next section. Section 3 defines the economic environment, characterizes theoretically efficient allocations for arbitrary Pareto weights, and defines our concept of equity. In Section 4 we define a political equilibrium. We first analyze the case under discretion, or "winner take all" solution in the spirit of Persson and Tabellini (1990), in Section 4.1. The bargaining protocol and the Markov-perfect equilibrium for a generic budget rule are described in Section 5. Section 6 characterizes a two-period model example to illustrate how these rules shape the equilibrium. The infinite-horizon dynamic model is solved quantitatively in Section 7 for a benchmark economy. Section 7.6 evaluates whether society is better off under rules or discretion, whereas Section 7.7 introduces the possibility of an institutional reform. Finally, Section 8 concludes and points venues for future research.

\section{Literature Review}

Our paper contributes to the literature studying redistributive policies and public good provision in the presence of political fictions. As in Lizzeri and Persico (2001), we analyze how alternative institutional arrangements can improve on allocations obtained under 'winner-take-all' systems. While they focus on proportional systems, we consider budget rules instead.

We model budget rules following the literature on legislative bargaining with endogenous status quo, along the lines of Baron and Ferejohn (1989). In our model, the tax code and the level of entitlement programs represent a status quo which remains in place unless some political group proposes an alternative allocation that is acceptable to the opposition. This mechanism creates a dynamic strategic link between the groups by impacting the trade-off faced by current policymakers, and imposes limits on the degree of redistribution, in the spirit of Diermeier, Egorov, and Sonin (2017). Because fiscal policy directly impacts private allocations-and the size of the endowment is fixed-our work is, more generally, related to papers analyzing divide-the-dollar games with multilateral bargaining. One branch of this literature focuses on the continuous space (e.g., Kalandrakis (2004), Kalandrakis (2010), Baron and Herron (2003), Anesi and Seidmann (2013), Nunnari (2018)), as in our theoretical analysis of the finite horizon model. The other branch restricts attention to choices in a discrete state space (e.g., Anesi (2010), Diermeier and Fong (2011), Diermeier, Prato, and Vlaicu (2016), and Duggan and Kalandrakis (2012)), as we do in the numer- 
ical implementation. A thorough discussion of the recent developments in the legislative bargaining literature with endogenous status quo can be found in Eraslan, Evdokimov, and Zápal (2020). One important departure from these papers is that we consider government policies that affect both, public and private goods. Moreover, we emphasize the distortions on public good provision arising from the bargaining process over private transfers. ${ }^{1}$

Our paper is also related to the literature determining the optimal provision of public goods in legislative bargaining models. ${ }^{2}$ The closest paper to ours is Bowen, Chen, and Eraslan (2014), who analyze the welfare implications of mandatory spending rules on public goods. They do not consider, however, rules on entitlement programs and taxes when public good provision is discretionary (and hence used as a bargaining chip). Their main finding is that a mandatory spending rule on public goods can restore Pareto efficiency. We find that this is not the case when budget rules control targeted transfers. Because the proposer can restrict the ability of the opposition to expropriate private resources by choosing fiscal policy instruments, the political equilibrium exhibits allocations that are distorted towards private consumption. Even though the two parties have the same preference for public goods, they end up in a situation in which there is significant volatility and under-provision of such goods. ${ }^{3}$ Our paper thus complements their findings by pointing out that the type of good targeted by the budget rule has important implications for its associated welfare gains in an environment where agents are risk averse. This finding is relevant because the largest mandatory spending programs in the United States are entitlements, which are mostly provided in the form of private transfers. There is an additional, and more subtle, difference between our paper and Bowen, Chen, and Eraslan (2014)'s work. A key underlying assumption in their model is the linearity in the utility of private goods. Because of linearity, fluctuations necessary to deliver the Samuelson level of public goods arising in the bargaining solution are inconsequential. In our environment, agents prefer smooth consumption profiles, so volatility of private consumption can generate significant welfare losses. ${ }^{4}$

Bouton, Lizzeri, and Persico (2020) study the effect of introducing entitlement programs in an environment with public good provision, but under a winner-take-all (or alternating dictator) approach, which is closest to our analysis under discretion. While they focus on the effects of entitlement programs on debt (which we abstract from by considering a balanced budget), we center on the impact of introducing budget rules through a legislative bargaining process determining the status quo values of taxes and entitlements.

The discussion of rules versus discretion (see Amador, Werning, and Angeletos (2006)), is also salient to our results. For example, Halac and Yared (2014) study the optimal level of discretion in fiscal policy when the economy faces persistent shocks. They show that when shocks are not i.i.d., an ex-ante optimal fiscal rule can create incentives for governments to accumulate maximal debt, becoming immiserated. Azzimonti, Battaglini, and Coate (2016) and Martin (2020) consider the welfare implications of balanced budget rules instead. We depart from these papers by considering mandatory rather than discretionary spending, but restricting the government ability to issue debt. Allowing for sovereign debt would be an interesting extension to our work. An excel-

\footnotetext{
${ }^{1}$ Battaglini and Coate (2007) and Battaglini and Coate (2008) do study legislative bargaining between private and public goods, but under the assumption of an exogenous status quo.

${ }^{2}$ For a cooperative bargaining approach to optimal public good provision, check Davila, Eeckhout, and Martinelli (2009).

${ }^{3}$ See Dziuda and Loeper (2016) and Dziuda and Loeper (2018) for environments where legislators are subject to preference shocks.

${ }^{4}$ Moreover, when we replicate their model with concave utility on private consumption, we find that mandatory spending rules on public goods do not restore Pareto efficiency (they do involve Pareto improvements, though). The solution under mandatory spending on public goods with concave utilities is detailed in a previous version of this paper, see Azzimonti et al. (2020).
} 
lent summary of the recent literature on budget rules in economies with 'winner take all' political systems featuring debt can be found in Yared (2019). For recent work on the effect of budget rules on debt mitigation in a bargaining game see Piguillem and Riboni (2020).

Our paper is also related to the literature studying the effects of power alternation on government policy, which includes Persson and Svensson (1989), Alesina and Tabellini (1990), Persson and Tabellini (2000), Acemoglu, Golosov, and Tsyvinski (2011) or Azzimonti (2011). These papers emphasize that political turnover introduces inefficiencies in a political equilibrium under discretion. We contribute to this literature by considering how budget rules can affect welfare in a model with legislative bargaining. Moreover, we show that the degree of persistence in proposal power is an important determinant of welfare gains associated with the introduction of entitlement programs. ${ }^{5}$ Considering concave utility functions over private consumption is key to our findings because individuals have preferences for smooth sequences of private and public consumption. This is an important departure from other papers studying the welfare consequences of budget rules. $^{6}$

Our contribution is both qualitative and computational. Adding concavity embeds more macroeconomic realism to the setting but also raises technical challenges for the computation of optimal policies. ${ }^{7}$ This is particularly the case when studying entitlement programs because it calls for solving for a large number of value and policy functions over a multidimensional state space. We add to the computational bargaining literature by complementing the work of Duggan and Kalandrakis (2012), and to the macroeconomic literature by extending the techniques of Gordon (2019) and Chatterjee and Eyigungor (2020) to a political-economy environment with legislative bargaining.

\section{Environment}

Consider a discrete-time infinite horizon economy populated by two types of agents, $R$ (rich) and $P$ (poor), of equal measure but different income levels, $y_{R}>y_{P}$. A draw of nature at the beginning of time determines the agent's type (with equal probability), and their type is fully persistent thereafter. Agents value private goods $c$ and public goods $g$ according to an additively separable instantaneous utility function $U(c, g)=u(c)+u(g)$ where $u$ is strictly increasing and concave in both arguments.

The government finances $g$ with lump-sum taxes on the rich, denoted by $\tau_{t}$, and on the poor, denoted by $\theta_{t}$, and can redistribute income through an entitlement program, implemented as a cash transfer $\tilde{e}_{t} \geq 0$ to poor agents at each point in time. Denoting by $e_{t}$ the net transfer that poor agents receive from the government, $e_{t}=\tilde{e}_{t}-\theta_{t}$, the government budget constraint (GBC) satisfies

$$
g_{t}+e_{t} \leq \tau_{t}
$$

The rich agents' consumption satisfies

$$
c_{R, t}=y_{R}-\tau_{t} .
$$

\footnotetext{
${ }^{5}$ Agenda setting power is exogenously determined in our model. See Agranov, Cotton, and Tergiman (2020) of an environment where it is endogenous instead.

${ }^{6}$ Bowen, Chen, Eraslan, and Zápal (2017) discuss how concavity affects the desirability of mandatory spending rules, but also abstract from entitlements.

${ }^{7}$ There are few papers in the legislative bargaining models with endogenous status quo which introduce macroeconomic features. Piguillem and Riboni (2011) considers taxation as an endogenous status quo in the neoclassical growth model, whereas Grechyna (2017) considers endogenous resources.
} 
Whereas the poor's consumption is given by

$$
c_{P, t}=y_{P}+e_{t} .
$$

Note that whereas entitlements $\tilde{e}_{t}$ are positive, net transfers $e_{t}$ need not be. We assume that there are constitutional constraints on the fiscal system ensuring a minimum level of consumption to all agents, $c_{i, t} \geq \bar{x}$ for $i \in\{R, P\}$, with $\bar{x} \geq 0$ and that there is a minimum amount of resources $\bar{x}_{g}>0$ that need to be devoted to public good provision, $g_{t} \geq \bar{x}_{g}$. We can interpret $\bar{x}_{g}$ as the minimum amount of resources needed to run government operations and maintain law and order in society. Hence, spending on public goods takes this value unless a policymaker chooses to spend more. These constraints impose restrictions on the net transfers received by poor agents and the level of taxes paid by the rich,

$$
e_{t} \geq \bar{x}-y_{P}, \quad \tau_{t} \leq y_{R}-\bar{x} \quad \text { and } \quad \tau_{t}-e_{t} \geq \bar{x}_{g} .
$$

For example, with $\bar{x}=0$, these bounds just restrict consumption of each agent to be nonnegative. In such case, net transfers to the poor can be negative because entitlements are not enough to cover their taxes $e_{t}=\tilde{e}_{t}-\theta_{t}<0$. With $\bar{x}=y_{P}$, we capture an environment where the poor never pay taxes (e.g. net transfers $e \geq 0$ ), so public goods are financed solely by the rich. The values of $\bar{x}$ and $\bar{x}_{g}$, together with the degree of income inequality $\Delta=y_{R}-y_{P}$, therefore, jointly determine the fiscal capacity of the government to finance public goods and the degree of redistribution that can be achieved. We will work under the assumption that $\bar{x}=y_{P}$, so that net transfers to the poor are given $e \geq 0$ and refer to $e$ simply as entitlements.

Equations (1)-(3) imply that the total income in the economy $Y=y_{R}+y_{P}$ must be enough to cover private and public consumption levels, as stated in the resource constraint below.

$$
c_{R, t}+c_{P, t}+g_{t} \leq Y
$$

With these, we can define allocations and evaluate lifetime utility as follows.

Definition 1. An allocation a is a sequence of private and public goods throughout the lifetime of an individual, $\mathbf{a}=\left\{c_{R, t}, c_{P, t}, g_{t}\right\}_{t=0}^{\infty}$. These allocations induce lifetime welfare $\mathcal{V}_{i}(\mathbf{a})$, for each individual type $i \in\{R, P\}$,

$$
\mathcal{V}_{i}(\mathbf{a})=\sum_{t=0}^{\infty} \beta^{t} U\left(c_{i, t}, g_{t}\right)
$$

given the discount factor $\beta \in(0,1)$.

\section{Efficient Allocations}

Before describing the political environment, it is useful to characterize the set of efficient allocations, to be used as one of our benchmark criteria.

Definition 2. An allocation is 'Pareto efficient' when a redistribution of resources (without loss) cannot improve the lifetime welfare of one of the agents without worsening that of the other agent.

The set of efficient allocations $\mathbf{a}^{*}$ can be traced-out by choosing sequences of private and public consumption in order to maximize a weighted sum of the lifetime utility of agents,

$$
\max _{\{\mathbf{a}\}}\left\{\lambda \mathcal{V}_{P}(\mathbf{a})+(1-\lambda) \mathcal{V}_{R}(\mathbf{a})\right\}
$$


subject to the resource constraint, eq. (5). The parameter $\lambda \in[0,1]$ denotes the Pareto-weight of poor agents. The solution is characterized in Proposition 1.

Proposition 1 The Pareto efficient allocations are time invariant. When $\lambda \in(0,1)$, they satisfy

$$
\begin{aligned}
c_{P, t}^{*} & =\Lambda_{P}(\lambda) Y, \\
c_{R, t}^{*} & =\Lambda_{R}(\lambda) Y, \\
g_{t}^{*} & =\left(1-\Lambda_{P}(\lambda)-\Lambda_{R}(\lambda)\right) Y
\end{aligned}
$$

with $\Lambda_{i}(\lambda) \in\left[0, \frac{1}{2}\right]$ defined in eq. (24) in Appendix 9.1, and

$$
\frac{\partial \Lambda_{P}(\lambda)}{\partial \lambda} \geq 0 \text { and } \frac{\partial \Lambda_{R}(\lambda)}{\partial \lambda} \leq 0 .
$$

At the extremes,

- $\lambda=0: c_{P, t}^{*}=0, c_{R, t}^{*}=\frac{Y}{2}$, and $g^{*}=\frac{Y}{2}$.

- $\lambda=1: c_{P, t}^{*}=\frac{Y}{2}, c_{R, t}^{*}=0$, and $g^{*}=\frac{Y}{2}$.

Proof. See Appendix 9.1.

The efficient level of the public good satisfies the "Samuelson rule," which requires that the social marginal benefit of providing the public good (e.g. the sum of private marginal benefits) is equated to the social marginal cost. Because there is a fixed endowment and no uncertainty, the allocation that maximizes problem (6) is time-invariant.

Figure 2 illustrates the combinations of lifetime welfare of rich and poor agents corresponding to the set of feasible efficient allocations (solid blue line). The set of such points is typically referred to as the Pareto Frontier, with each point associated to a specific value of $\lambda$. The most upper-left point in the frontier corresponds to $\lambda=0$, where poor agents receive no weight (and hence the lowest possible level of consumption) and rich agents enjoy the highest welfare. The most lowerright point in the frontier corresponds to the case where $\lambda=1$, where poor agents achieve the highest lifetime welfare and rich agents the lowest (because their private consumption is minimal).

Higher values of the weight $\lambda$ are associated with more private consumption for poor agents and less consumption for rich ones. The net effect on $g$ depends on the shape of the utility function. For example, when utility is logarithmic, the efficient level of public goods is independent of the Pareto weights, as shown in the following corollary.

Corollary 1 When $u()=.\log ($.$) , the Pareto efficient allocations satisfy$

$$
\begin{aligned}
g_{t}^{*} & =\frac{Y}{2}, \\
c_{P, t}^{*} & =\frac{\lambda Y}{2}, \\
c_{R, t}^{*} & =\frac{(1-\lambda) Y}{2} .
\end{aligned}
$$

Proof. See Appendix 9.2. 
It is easy to see that the efficient allocations can be decentralized with time-invariant taxes and entitlements as follows

$$
\tau^{*}=y_{R}-\Lambda_{R}(\lambda) Y \quad \text { and } \quad e^{*}=\Lambda_{P}(\lambda) Y-y_{P}
$$

The degree of redistribution implied by these fiscal policies depends on the value of the Paretoweights. For example, $\lambda=0.5$ would result in a combination of taxes and entitlements that achieve significant redistribution from rich to poor agents, equating their consumption levels at every point in time, $c_{R}=c_{P}$.

\section{Equitable Allocations}

It is standard in studies of optimal taxation to focus on Pareto efficient allocations in order to measure distortions from alternative fiscal policy plans. The underlying assumption is that if the policymaker had access to a complete set of instruments, she would be able to redistribute resources to achieve desirable societal outcomes. In other words, we typically work under the assumption that the Second Welfare Theorem holds.

The point of departure of this paper is different. We assume that policymakers have access to a complete set of fiscal policy instruments but that individuals disagree on the direction of policy once they know their type (i.e. at birth, in the first period). Rich agents would like a policymaker with $\lambda=0$, whereas poor agents would prefer one with $\lambda=1$. If either of them was entitled to choose policy moving forward-without institutional constraints-, the resulting allocations would be efficient (e.g. at the endpoints of the Pareto Frontier), but they would be associated with significantly different levels of lifetime welfare. In other words, they would not be equitable.

Definition 3. An allocation is 'equitable' when it is associated with the same level of lifetime welfare for all agents in society.

We define equitable allocations $\mathbf{a}^{e}$ as those which give the same lifetime utility to agents of each type, $\mathcal{V}_{R}\left(\mathbf{a}^{e}\right)=\mathcal{V}_{P}\left(\mathbf{a}^{e}\right) \equiv \mathcal{V}\left(\mathbf{a}^{e}\right)$. The literature sometimes refers to this as Vertical Equity and the allocations that generate them as Envy-Free allocations (see Hylland and Zeckhauser, 1979 or more recently Echenique Miralles, and Zhang, 2019). ${ }^{8}$ The combinations of welfare associated to feasible equitable allocations $\mathbf{a}^{e}$ is illustrated in Figure 2 (solid red line), labeled the Equitable Line. It corresponds to a $45^{\circ}$ line from the origin up to the Pareto Frontier.

\section{Optimal Allocations}

From the figure, we can see that there are allocations which are efficient but not equitable (such as B), while others are equitable but inefficient (such as A).

Definition 4. An allocation is 'optimal' when it is both, efficient and equitable.

The trade-off between equity and efficiency depends on the specific shape of the social welfare function. While there is no consensus about the particular functional form, a useful benchmark

\footnotetext{
${ }^{8} \mathrm{An}$ allocation is envy-free if the level of welfare of agent $i$ would increase if she were assigned $j$ 's private consumption allocation (and vice-versa). In other words, if no agent could get higher welfare by receiving another agents' assigned allocation.
} 


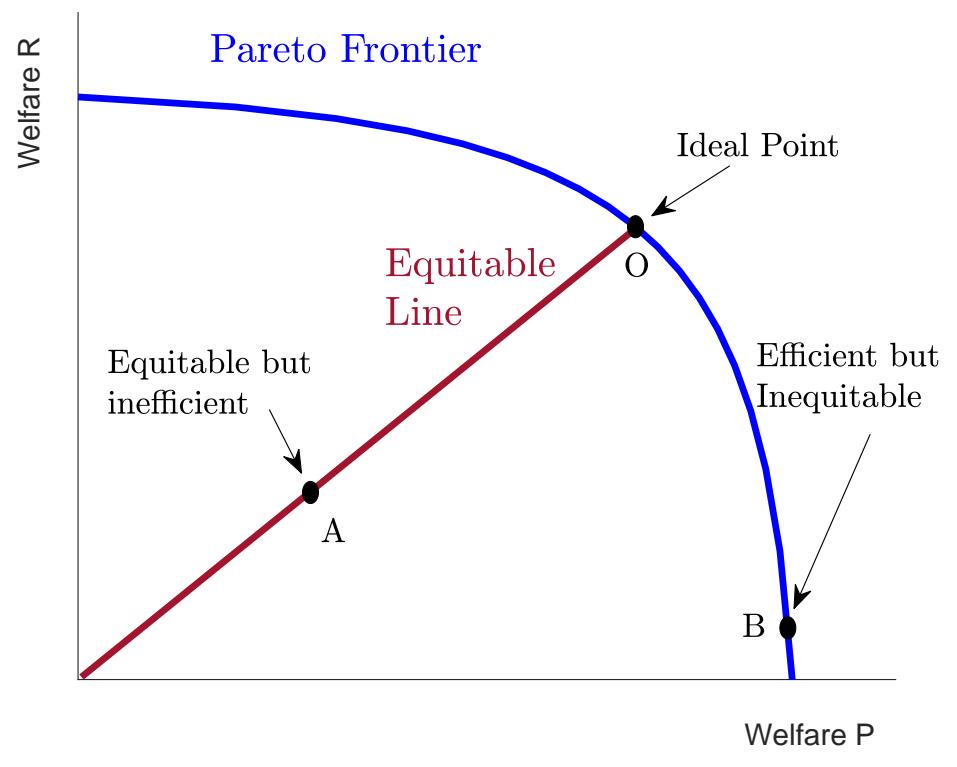

Figure 2: Efficient vs Equitable Allocations

typically used is the Utilitarian Welfare Function, which corresponds to a case where both agents are given equal weight,

$$
\mathcal{W}(\mathbf{a})=\frac{1}{2} \mathcal{V}_{R}(\mathbf{a})+\frac{1}{2} \mathcal{V}_{P}(\mathbf{a})
$$

The optimal allocation according to this function, which we will denote by $\mathbf{a}^{\mathrm{O}}$ is both efficient and equitable. This is because it is on the Pareto Frontier (e.g. $\lambda=0.5$ ) and because it results in equal level of welfare for all agents in society. In the plot, it corresponds to point $\mathrm{O}$, where the Equitable Line intersects the Pareto Frontier. Optimal allocations can be obtained form Proposition (1),

$$
g_{t}^{o}=(1-2 \Lambda) Y \quad \text { and } \quad c_{i, t}^{o}=\Lambda Y,
$$

with $\Lambda=\Lambda_{P}(0.5)$ and $i \in\{R, P\}$. When $u(x)=\log (x)$, the planner devotes half of the pie $Y$ to private goods and splits the rest evenly between the two agents $(\Lambda=0.25)$,

$$
g_{t}^{o}=\frac{Y}{2}, \quad \text { and } \quad c_{i, t}^{o}=\frac{Y}{4} .
$$

Note that if agents were asked about their most preferred allocation under a veil of ignorance, i.e. before their type was revealed at birth, they would both agree on $\mathrm{O}$ being the ideal point. This is the case because we assumed that agents could be rich or poor with equal probability. Ex-post, on the other hand, they prefer to be at one of the extremes of the Pareto Frontier. This inconsistency in preferences, paired with an inability to commit to institutions ensuring an efficient and equitable allocation, is what gives raise to political parties in our model. Hence, our main friction is not distortionary taxation, but instead disagreement between individuals in society.

In the next sections, we consider alternative political environments and evaluate the resulting allocations in terms how efficient and equitable they are. 


\section{Political Equilibrium}

Because of income inequality, individuals of different income groups disagree on fiscal policy. As a result, political parties naturally arise in this environment. We assume that there are two parties: $R$ and $P$ representing the interest of agents in each group. Allocations are chosen by a representative of one of two groups, like in the citizen candidate models of Osborne and Slivinski (1996) or Besley and Coate (1997). The identity of the active ruler is immaterial as individuals are homogeneous within a group. Each period, an incumbent chooses current-period fiscal policy (e.g. public goods, taxes, and entitlements) in order to maximize the utility of her constituency, knowing that she will be re-elected with (exogenous) probability $q$.

We focus on Stationary Markov Perfect Equilibria (MPE). A MPE is a Subgame Perfect Equilbria (SPE) in which strategies are restricted to be stationary Markovian. A strategy profile is stationary Markovian if, for any two ex post histories that terminate in the same state, the strategies that follow are the same. ${ }^{9}$ This restriction is not without loss of generality. After all, stationary Markovian strategies ignore all details of a history of plays. Much of the applied work of dynamic games has focused on the use of stationary Markovian strategies not only for their simplicity, but also for their prediction power as Folk-like results can be prevented. Moreover, it seems reasonable in a variety of settings to require strategies to rely only on relevant information at the time of the play. In fact, if the dynamic interaction of parties is seen as an infinite game played by a sequence of politicians who face uncertain reelection, the restrictions of Markovian strategies is justifiable. See Bhaskar et al. (2013) for a discussion of the restriction to Markov strategies.

Before discussing the political equilibrium with bargaining over taxes and entitlement programs, it is enlightening to characterize the solution under discretion where parties alternate in power stochastically.

\subsection{Policy under Discretion}

This environment, commonly used in the literature (see Persson and Tabellini (2000), among others), is typically referred to as the 'winner takes all' election model. Here, the policymaker in power does not need the other party's approval to implement a given policy. Because of this, it is also known as the 'alternating dictator' model.

Since power alternation follows a Markov process, it is easier to write the problem of an incumbent recursively. To fix ideas, suppose that $P$ is in power and let $V_{P}^{D}$ denote her value function when in power and $W_{P}^{D}$ when out of power. Then,

$$
V_{P}^{D}=\max _{\{\tau, e, g\}}\left\{U(c, g)+\beta\left[q V_{P}^{D}+(1-q) W_{P}^{D}\right]\right\}
$$

subject to the government budget constraint (1), the consumer budget constraints (2) and (3), and the bounds eq. (4). Because total income is constant over time and the government is subject to a balanced budget, there is no dynamic state variable in this economy. Therefore, the problem of an incumbent choosing policies under discretion is static.

Proposition 2 Fiscal policy under discretion satisfies

$$
\begin{aligned}
& \text { P in power: } \tau_{P}^{D}=y_{R}-\bar{x} \text { and } e_{P}^{D}=\frac{\Delta-\bar{x}}{2} . \\
& \text { R in power: } \tau_{R}^{D}=\frac{\Delta+\bar{x}}{2} \quad \text { and } \quad e_{R}^{D}=\bar{x}-y_{P},
\end{aligned}
$$

\footnotetext{
${ }^{9}$ For a more precise definition of stationary Markovian strategies see Mailath and Samuelson (2006).
} 
where $\Delta=y_{R}-y_{P}$ denotes income inequality. The resulting allocations when $i$ is the incumbent are given by

$$
g^{D}=\frac{Y-\bar{x}}{2}, \quad c_{i, i}^{D}=g^{D}, \quad \text { and } \quad c_{j, i}^{D}=\bar{x} \quad \text { for } j \neq i .
$$

Proof. See Appendix 9.3

The incumbent expropriates the other group as much as possible, providing them with the minimum feasible level of consumption when in power. When $P$ is the incumbent, taxes on the rich are maximal, $\tau_{P}^{D}=y_{R}-\bar{x}$ whereas their consumption hits the lower bound $c_{R, P}^{D}=\bar{x}$. The remaining of the budget is split evenly between the public good and the consumption of the poor, $c_{P, P}^{D}=g^{D}$. This results follows from the assumption that $g$ and $c$ have the same weight (and curvature) in the utility function of agents. When $R$ is the proposer, net transfers to the poor are minimal, so they consume at $c_{P, R}^{D}=\bar{x}$. Note that while the two parties disagree on the burden of taxation, they both choose the same provision of public goods, $g^{D}=\frac{\gamma-\bar{x}}{2}$ and the total level devoted to private consumption $c^{D}=c_{R, i}^{D}+c_{P, i}^{D}$. Hence, public good provision and total consumption do not depend on the identity of the party in power. When $\bar{x}=0$, public goods satisfy the Samuelson rule $g^{D}=g^{*}$. We discuss how politics affects equity and efficiency next.

\subsection{Political Inequities and Inefficiencies}

Suppose that party $P$ is the incumbent this period and let $\bar{x}=0$. Statically, the choice under discretion is efficient, since it correspond to the solution of Problem 6 for $\lambda=1$. This can be seen by comparing the expressions in Proposition 1, given $\lambda=1$, to those characterized in Proposition 2. Moreover, if $q=1$ so that poor agents were always in power, the solution under discretion is efficient even in a dynamic sense. This allocation, however, is highly inequitable as it is at significant distance from the Equitable Line. When one the of groups is in power forever, the other group consumes the minimum level of consumption $\bar{x}$, and hence has much lower welfare than the group in power. The degree of inequity depends on the value of $\bar{x}$, and it is maximal as $\bar{x} \rightarrow 0$.

When there is alternation in power, the solution under discretion is no longer efficient, as shown in the next Corollary.

Corollary 2 Let $\bar{x}=0$. For any $q \in(0,1)$, the allocations under discretion are Pareto inefficient.

With political turnover, the levels of consumption enjoyed by each group fluctuate between $\frac{Y}{2}$ and $\bar{x}$, depending on the identity of the incumbent, whereas the efficient ones are constant. Curvature in the utility function of agents implies that they would prefer a smooth consumption sequence to a volatile one. In a political equilibrium, the volatility induced by power alternation reduces lifetime utility, and it is a dynamic source of inefficiency in this model.

Corollary 3 When $\bar{x}>0$, there is under-provision of public goods and over-provision of private goods under discretion

$$
g^{D}<g^{*} \text { and } c^{D}>c^{*}
$$

where $c^{D}=c_{R, i}^{D}+c_{P, i}^{D}$ and $c^{*}=c_{R}^{*}+c_{P}^{*}$.

Proof. See Appendix 9.4

The solution under discretion when $\bar{x}>0$ never satisfies the Samuelson rule. This happens because the incumbent equates the marginal cost of public goods to her private marginal benefit, 
whereas the planner would equate it to the social marginal benefit. In other words, incumbent $i$ ignores the welfare gains to group $j$ of providing $g$ and this results in over-provision of private goods and under-provision of public goods, regardless of the identity of the incumbent. Despite of this, without power alternation, it is still possible to reach a point in the Pareto Frontier. The main reason is that policy instruments are non-distortionary and allocations are time-invariant with $q=1$. The lower bound $\bar{x}$ rules out extreme values in the frontier, but it is easy to show that there exists a value of $\lambda$ such that the allocations under discretion deliver a point in the frontier.

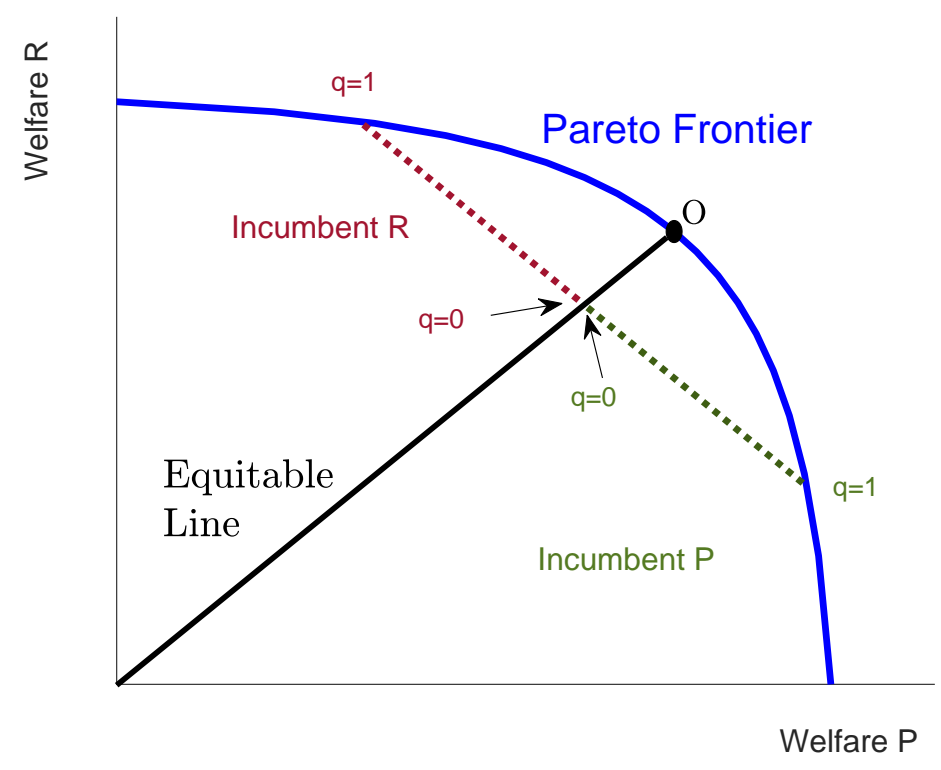

Figure 3: Pareto Frontier vs Solution under Discretion.

Figure 3 illustrates this. ${ }^{10}$ The figure depicts pairs of lifetime utility attained by each type of agent in the first-best and under discretion for a situation where utility is logarithmic and $\bar{x}>$ 0 . The dashed garnet line represents welfare combinations for the solution under discretion at different values of $q$, assuming that $R$ is the incumbent. That is, each point in the line is a pair $\left(W_{P}^{D}, V_{R}^{D}\right)$ for a specific value of $q$. The only point at which the welfare under discretion is not smaller than in the first best is that where $q=1$ (e.g. under no power alternation). As we decrease the probability of re-election of the incumbent, welfare moves further inside the Pareto Frontier. The dashed green line corresponds to the case where $P$ is the incumbent; as $q$ increases, welfare for that group rises. This case corresponds to pairs $\left(V_{P}^{D}, W_{R}^{D}\right)$ for different $q$ values.

A key message from this analysis is that there are two sources of Pareto inefficiency under discretion when $q<1$. The first one is a static inefficiency which arises because, to the extent that $\bar{x}>0$, the incumbent under-provides public goods relative to the planner. The second one is dynamic and arises because private consumption fluctuates with the identity of the incumbent. Allowing for power alternation does have a benefit to society. By changing the decision-maker every period, the political system enables more equitable allocations. This can be seen by the fact that lifetime-welfare pairs associated to lower values of $q$ (e.g. as we move from the extremes to the center in the dashed lines) are closer to the Equitable Line. Political instability, thus, is detrimental for efficiency but beneficial for equity in this model. In general, allocations are most equitable when there is deterministic alternation in power, so $q=0$.

\footnotetext{
${ }^{10}$ The parameters used to construct the figure are $\beta=0.96, Y=1.3$ and $\bar{x}=0.1$. The instantaneous utility function is $u(x)=\ln (x)$.
} 
Interestingly, the Utilitarian planner is indifferent between all the allocations along the dashedgarnet or dashed-green lines. This is because the problem is completely symmetric, so $\mathcal{W}\left(\mathbf{a}^{d}\right)$ is independent of $q$. In other words, the welfare pairs for different values of $q$ belong to the same indifference curve. ${ }^{11}$

Budget rules that alleviate the first source of inefficiency (e.g. distorted provision of private and public goods) have been studied previously, e.g. Bowen et al. (2014): a proposed way to improve on the allocation is to introduce mandatory spending on public goods $g$. The second source of inefficiency (e.g. fluctuations in private consumption) is well understood in the political macro-economic literature but it has been less studied in the bargaining literature with endogenous status quo, which typically assumes it away by considering linear utility functions over private consumption. Under concavity, it is also relevant to consider how bargaining over fiscal policies, which introduce persistence in private allocations, affect welfare. In what follows, we consider a situation where changing the tax code and the size of the entitlement program requires a consensus.

\section{Political Equilibrium with Bargaining}

In this section, we analyze an economy subject to budget rules. More specifically, we assume that changing entitlement programs and taxes require bipartisan support. In contrast to the previous section, where the incumbent was a dictator within the period and was able to choose fiscal policy freely, these variables can no longer be chosen unilaterally. More specifically, we model taxes and entitlements as governed by criteria set by enacted law. This implies that unless a majority of legislators chooses to change such laws, $\tau$ and $e$ must take last period's values. We will refer to them as the tax code and entitlement programs. Public goods, on the other hand, are considered to be discretionary spending. As such, there is no pre-determined value for $g$ in the tax system. Hence, spending on public goods takes the minimum value $\bar{x}_{g}$ unless there is an explicit agreement by the two parties to spend more.

\subsection{Bargaining Protocol}

The relevant state variables in this economy are $\mathbf{s}=\{\bar{\tau}, \bar{e}\}$, representing taxes to the rich and net transfers to the poor implemented in the previous period. The current incumbent takes them as given, as they determine status-quo values in case a proposal is rejected.

To fix ideas, suppose that the incumbent is of type $P$. At the outset of this period, $P$ makes a feasible fiscal policy proposal for government spending $g$ and for taxes to the rich and net transfers to the poor, $\pi_{P}=\{\tau, e\}$. Party $R$ can accept or reject the proposal, $d_{R}(\mathbf{s}) \in\{0,1\}$, where $d_{R}(\mathbf{s})=1$ denotes that the proposal has been accepted. The tie-breaking rule favors any proposed allocation, i.e., if the respondent is indifferent between the status quo and a new proposed policy, we assume that the respondent accepts. If the proposal is accepted, its associated allocation is implemented and becomes the new state, $\mathbf{s}^{\prime}=\pi_{P}$. If the proposal is rejected, the status quo allocation from $\mathbf{s}$ is implemented, and next period's state remains the same, $\mathbf{s}^{\prime}=\mathbf{s}$. The probability of retaining proposal power is given by $q$. In contrast to the problem under discretion, which was static, there is a dynamic component in this environment since the outcome of the bargaining problem becomes the endogenous status quo for next period.

\footnotetext{
${ }^{11}$ The indifference curves for the Utilitarian planner are determined by $\mathcal{V}_{R}(\mathbf{a})=\overline{\mathcal{W}}-\mathcal{V}_{P}(\mathbf{a})$, where $\overline{\mathcal{W}}$ is a given value of welfare. Hence, they are straight lines with a slope of -1 .
} 


\subsection{Markov Perfect Equilibrium}

Under this equilibrium concept, policy functions only depend on payoff-relevant states of the economy, given by $\mathbf{s}=\{\bar{\tau}, \bar{e}\}$. Due to the existence of income inequality, equilibrium policy rules depend on the identity of the incumbent. We denote by $\mathcal{G}_{i}(\mathbf{s})$ the MPE policy for public goods chosen by incumbent $i$, whereas $\Psi_{i}(\mathbf{s})$ denotes the rule determining taxes imposed on the rich and $\mathcal{E}_{i}(\mathbf{s})$ the equilibrium policy determining net transfers to the poor. Consumption allocations of agent $j$ determined by incumbent $i$ are denoted with $\mathcal{C}_{j, i}(\mathbf{s})$. The associated continuation utilities are $V_{i}\left(\mathbf{s}^{\prime}\right)$ if the incumbent remains the proposer next period and $W_{i}\left(\mathbf{s}^{\prime}\right)$ if out of power.

Suppose that $P$ is the current proposer, her maximization problem can be written as

$$
\max _{\{\tau, e, g\}} u\left(c_{P}\right)+u(g)+\beta\left\{q V_{P}\left(\pi_{P}\right)+(1-q) W_{P}\left(\pi_{P}\right)\right\}
$$

where we used the fact that on the equilibrium path the proposal is accepted, $\mathbf{s}^{\prime}=\pi_{P}=\{\tau, e\}$. The constraints are eqs. (1)-(4), and the acceptance constraint

$$
\begin{gathered}
u\left(c_{R}\right)+u(g)+\beta\left\{(1-q) V_{R}\left(\pi_{P}\right)+q W_{R}\left(\pi_{P}\right)\right\} \geq \\
u\left(\bar{c}_{R}\right)+u\left(\bar{x}_{g}\right)+\beta\left\{(1-q) V_{R}(s)+q W_{R}(s)\right\}
\end{gathered}
$$

with $\bar{c}_{R}=y_{R}-\bar{\tau}$. The bottom part of the equation denotes the dynamic payoff to the opposition party when the proposal is rejected, that is, the payoff from keeping the status quo. Recall that when no agreement is reached, $g=\bar{x}_{g}$. The acceptance constraint ensures that the proposal is accepted if and only if the payoff from the proposal is individually rational for the respondent, i.e., it provides a payoff that is at least as high as the payoff under the status quo $s$. The expression makes it clear that the budget rule defines a lower bound for the welfare level attained by the opposition $R$. It also makes it clear that the lower bound $\bar{x}_{g} \geq 0$ controls how binding equation (11) is at every point in time. When $\bar{x}_{g}$ is very small, rejecting a proposal can be very costly for the opposition, so larger deviations from the status quo will become attainable for the proposer.

The acceptance constraint of party $P$ when $R$ is in power is similarly defined,

$$
\begin{gathered}
u\left(c_{P}\right)+u(g)+\beta\left\{(1-q) V_{P}\left(\pi_{R}\right)+q W_{P}\left(\pi_{R}\right)\right\} \geq \\
u\left(\bar{c}_{P}\right)+u\left(\bar{x}_{g}\right)+\beta\left\{(1-q) V_{P}(s)+q W_{P}(s)\right\}
\end{gathered}
$$

with $\bar{c}_{P}=y_{P}+\bar{e}$ instead.

Finally, we have that in the MPE, the value function of a type- $P$ incumbent satisfies

$$
V_{P}(\mathbf{s})=u\left(\mathcal{C}_{P, P}(\mathbf{s})\right)+u\left(\mathcal{G}_{P}(\mathbf{s})\right)+\beta\left\{q V_{P}\left(\Pi_{P}(\mathbf{s})\right)+(1-q) W_{P}\left(\Pi_{P}(\mathbf{s})\right)\right\}
$$

with next period's status quo given by today's equilibrium choices by incumbent $P$, namely $\Pi_{P}(\mathbf{s})=\left\{\Psi_{P}(\mathbf{s}), \mathcal{E}_{P}(\mathbf{s})\right\}$. The value function of type $P$ when out of power satisfies

$$
W_{P}(\mathbf{s})=u\left(\mathcal{C}_{P, R}(\mathbf{s})\right)+u\left(\mathcal{G}_{R}(\mathbf{s})\right)+\beta\left\{(1-q) V_{P}\left(\Pi_{R}(\mathbf{s})\right)+q W_{P}\left(\Pi_{R}(\mathbf{s})\right)\right\}
$$

as policies are chosen by party $R$ in such case, with $\Pi_{R}(\mathbf{s})=\left\{\Psi_{R}(\mathbf{s}), \mathcal{E}_{R}(\mathbf{s})\right\}$. We can now formally define the Markov perfect equilibrium for the game. 
Definition 5. A MPE with legislative bargaining is a set of value functions $\left\{V_{i}(\mathbf{s}), W_{i}(\mathbf{s})\right\}$, policy func-

tions $\Pi_{i}(\mathbf{s})=\left\{\Psi_{i}(\mathbf{s}), \mathcal{E}_{i}(\mathbf{s})\right\}$, allocations $\left\{\mathcal{C}_{j, i}(\mathbf{s}), \mathcal{G}_{i}(\mathbf{s})\right\}$, and acceptance rules $d_{j}(\mathbf{s})$ for incumbent $i$ and opposition $j \neq i$ where $i, j \in\{R, P\}$, such that

- Proposer P chooses public good $g$ and fiscal policy $\pi_{P}=\{\tau, e\}$ to maximize problem (10) subject to the budget constraints eqs. (1)-(3), the bounds eq. (4), and the acceptance constraint, eq. (11). Given the value functions $V_{P}(\mathbf{s})$ and $W_{P}(\mathbf{s})$, the acceptance decision $d_{R}(\mathbf{s})$, and the rules chosen by the opposition party $R, \Pi_{R}(\mathbf{s})$, these define the policy functions $\Pi_{P}(\mathbf{s})$. The problem of proposer $R$ is analogously defined.

- Given the policy functions $\Pi_{R}(\mathbf{s})$ and $\Pi_{P}(\mathbf{s})$, the value functions $V_{P}(\mathbf{s})$ and $W_{P}(\mathbf{s})$ satisfy equations (12) and (13), respectively. The value functions $V_{R}(\mathbf{s})$ and $W_{R}(\mathbf{s})$ are analogously defined.

- Given $V_{P}(\mathbf{s})$ and $W_{P}(\mathbf{s})$, for any proposal $\pi_{P}$ and status quo $s$, the acceptance strategy $d_{R}(\mathbf{s})=1$ if and only if eq. (11) holds. The acceptance rule $d_{P}(\mathbf{s})$ is analogously defined.

The first condition states that policy rules are the ones that solve the problem of the proposer, given continuation utilities and an acceptance rule for the opposition party. The second condition defines value functions as a fixed point using policy functions under an accepted proposal. The last condition determines that the opposition party accepts the proposal whenever its welfare is at least as large as under the status quo.

\section{Two-Period Model}

Before characterizing the infinite-horizon version of the model, it is illustrative to consider a twoperiod version of the model. Given that this is a two-person, two-period, complete information extensive form game, we can focus on its unique subgame perfect equilibrium (SPE). The secondperiod strategies do not depend on histories except through the status quo. The problem can be solved backwards. We start with the full characterization of the second-period optimum strategies of party $i$. The infinite-horizon dynamic model is studied in Section 7.1.

\subsection{Second-Period Characterization.}

The second-period incumbent takes the status quo $\mathbf{s}=\{\bar{\tau}, \bar{e}\}$ as given. Because the economy ends this period, there is no continuation utility. The analysis allows us to understand how the status quo affects the choice set and the relative bargaining power of the two groups, while ignoring the dynamic consequences of this choice.

Incumbent $P$ proposes $\left\{g_{2}, \tau_{2}, e_{2}\right\}$, given status quo $s$, in order to maximize her static payoff,

$$
\begin{array}{r}
\max _{\left\{\tau_{2}, e_{2}, g_{2}\right\}} u\left(c_{P, 2}\right)+u\left(g_{2}\right) \quad \text { s.t. } \\
u\left(c_{R, 2}\right)+u\left(g_{2}\right) \geq u\left(y_{R}-\bar{\tau}\right)+u\left(\bar{x}_{g}\right),
\end{array}
$$

and eqs. (1)-(4),

The acceptance constraint, eq. (14), ensures that the proposal is accepted if and only if the payoff from the proposal is higher than the payoff under the status quo $s$. In the analysis that follows, we assume that the utility is logarithmic and $\bar{x}_{c}=\bar{x}_{g} \equiv \bar{x}$, as it greatly facilitates exposition. 
Proposition 3 Let utility be logarithmic $u()=.\ln ($.$) and \bar{x}_{c}=\bar{x}_{g} \equiv \bar{x}$. In the last period, the unique equilibrium proposal for incumbent $P$ satisfies:

$$
\mathcal{E}_{P, 2}(s)=\left\{\begin{array}{ll}
\frac{\Delta}{2}-\frac{2 \bar{x}\left[y_{R}-\bar{\tau}\right]}{Y}, & \text { if } \bar{\tau}<\frac{\Delta}{2} \\
\bar{\tau}-\bar{x}, & \text { if } \bar{\tau} \in\left[\frac{\Delta}{2}, \tau_{R}^{D}\right) \\
e_{P}^{D}, & \text { if } \bar{\tau} \geq \tau_{R}^{D} .
\end{array} \quad \Psi_{P, 2}(s)= \begin{cases}y_{R}-\frac{2 \bar{x}\left[y_{R}-\bar{\tau}\right]}{Y}, & \text { if } \bar{\tau}<\frac{\Delta}{2} \\
\tau_{P}^{D}, & \text { if } \bar{\tau} \in\left[\frac{\Delta}{2}, \tau_{R}^{D}\right) \\
\tau_{P}^{D}, & \text { if } \bar{\tau} \geq \tau_{R}^{D} .\end{cases}\right.
$$

and

$$
\mathcal{G}_{P, 2}(s)= \begin{cases}g^{*}, & \text { if } \bar{\tau}<\frac{\Delta}{2} \\ y_{R}-\bar{\tau}, & \text { if } \bar{\tau} \in\left[\frac{\Delta}{2}, \tau_{R}^{D}\right) \\ g^{D}, & \text { if } \bar{\tau} \geq \tau_{R}^{D} .\end{cases}
$$

The associated private consumption allocations are

$$
\mathcal{C}_{P, P, 2}(s)=y_{P}+\mathcal{E}_{P, 2}(s) \text { and } \mathcal{C}_{R, P, 2}(s)=y_{R}-\Psi_{P, 2}(s) .
$$

Proof. See Appendix 9.5.

The only relevant state variable for proposer $P$ is the status quo level of taxes on the rich, $\bar{\tau}$. This is the case because the rich use their veto power to block policy changes that deliver welfare levels below those obtained under the status quo. The effect of alternative $\bar{\tau}$ values is illustrated in Figure 4 for a numerical example with $Y_{R}=1.2, Y_{P}=0.1$, and $\bar{x}=0.1$, where we plot equilibrium policies (top panel) and allocations (bottom panel) as functions of $\bar{\tau}$. When $\bar{\tau} \geq \tau^{D}$, status quo taxes on the rich are so large that the proposer is able to implement policies under discretion, $\tau_{P}^{D}$ and $e_{P}^{D}$. In this case, the acceptance constraint is not binding, so the proposer just equates her marginal utility of private consumption to that of public consumption, implying $\mathcal{G}_{P, 2}(s)=g^{D}$ and $\mathcal{C}_{P, P, 2}(s)=c_{P, P}^{D}$.

When intermediate taxes are established in the tax code, $\bar{\tau} \in\left[\frac{\Delta}{2}, \tau_{R}^{D}\right)$, proposing policies under discretion is no longer acceptable for the opposition. Group $R$ is better off rejecting the proposal and keeping taxes and entitlements at their status quo values. Anticipating this, proposer $P$ offers an alternative mix enough to guarantee the opposition's minimum welfare under the status quo, so that constraint (14) becomes binding, but that make $P$ slightly better off. In order to induce the opposition to accept the proposal, incumbent $P$ needs to either impose lower taxes (e.g. increase $c_{R, 2}$ above the minimum $\bar{x}$ ) or provide more public goods at the expense of her own consumption (through lower entitlements). Given that $P$ enjoys consuming public goods (but derives no utility from the opposition's private consumption), it is best to offer $\tau_{P}^{D}$ and instead reduce entitlements below $e_{P}^{D}$. This results in higher provision of public goods and a slightly lower $c_{P}$ than under discretion. The rich are willing to accept this proposal even though their consumption is set at the lower bound. When taxes are below $\frac{\Delta}{2}$, the opposition has so much bargaining power, that incumbent $P$ is forced to reduce taxes and entitlements even further. The only proposal that would give $P$ high consumption involves $g_{2}=g^{*}$, the Samuelson level of the public good provision. Interestingly, consumption inequality is minimal when taxes on the rich are low, despite the built in mechanism to have more equality through entitlement programs. This is the case because low taxes give more bargaining power to rich agents when $P$ is in power, limiting the poor's ability to expropriate the rich.

For completeness, it is useful to characterize the policy rules that would be chosen by incumbent type $R$ if in power in the second period under the assumptions of Proposition 3. 

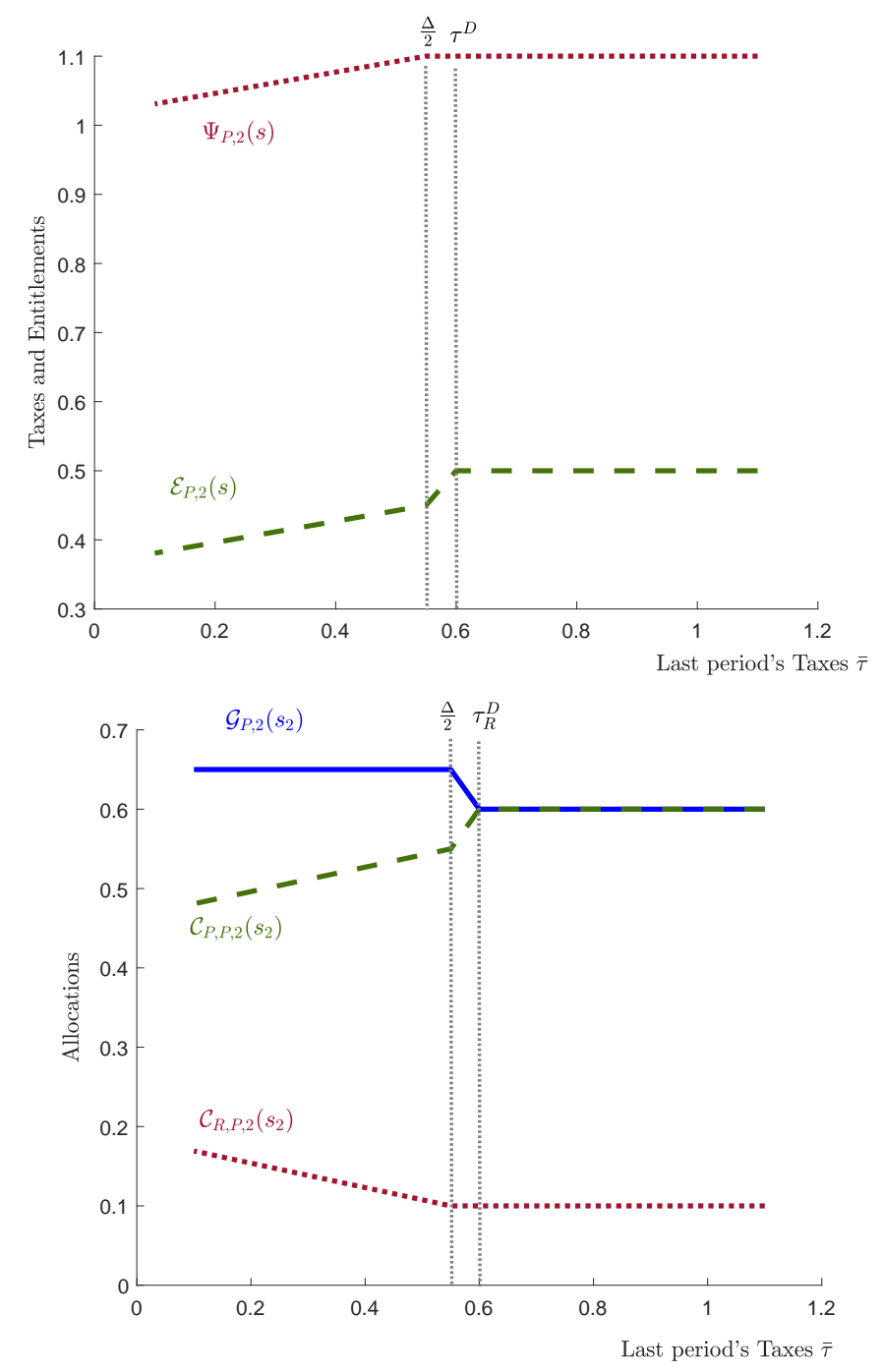

Figure 4: Second period policies and allocations under incumbent $P$.

Proposition 4 Let utility be logarithmic $u()=.\ln ($.$) and \bar{x}_{c}=\bar{x}_{g} \equiv \bar{x}$. In the last period, the unique equilibrium proposal for incumbent $R$ satisfies:

$$
\begin{gathered}
\mathcal{E}_{R, 2}(s)=\left\{\begin{array}{ll}
e_{R}^{D}, & \text { if } \bar{e}<e_{P}^{D} \\
e_{R}^{D}, & \text { if } \bar{e} \in\left[e_{P}^{D}, \frac{\Delta}{2}\right) \\
\frac{2 \bar{x}\left[y_{P}-\bar{e}\right]}{Y}-y_{P}, & \text { if } \bar{e} \geq \frac{\Delta}{2} .
\end{array} \quad \Psi_{R, 2}(s)= \begin{cases}\tau_{R}^{D}, & \text { if } \bar{e}<e_{P}^{D} \\
\bar{x}-\bar{e}, & \text { if } \bar{e} \in\left[e_{P}^{D}, \frac{\Delta}{2}\right) \\
\frac{\Delta}{2}+\frac{2 \bar{x}\left[y_{P}-\bar{e}\right]}{Y} & \text { if } \bar{e} \geq \frac{\Delta}{2},\end{cases} \right. \\
\mathcal{G}_{R, 2}(\boldsymbol{s})= \begin{cases}g^{D}, & \text { if } \bar{e}<e_{P}^{D} \\
y_{P}+\bar{e}, & \text { if } \bar{e} \in\left[e_{P}^{D}, \frac{\Delta}{2}\right) \\
g^{*}, & \text { if } \bar{e} \geq \frac{\Delta}{2} .\end{cases}
\end{gathered}
$$

with associated consumption $\mathcal{C}_{P, R, 2}(s)=y_{P}+\mathcal{E}_{R, 2}(s)$ and $\mathcal{C}_{R, R, 2}(s)=y_{R}-\Psi_{R, 2}(s)$.

Proof. See Appendix 9.6. 
For an $R$ incumbent, the relevant thresholds are determined by the status quo level of net transfers to the poor $\bar{e}$. Under the assumption that $\bar{x}=y_{P}$ these are just thresholds on entitlement levels. The intuition behind the solution above is analogous to the one described before. When existing law establishes a low level of entitlements, a rich proposer has no incentives to choose something different from discretion, which is her best unconstrained choice. As $\bar{e}$ exceeds the first threshold (but not the second), the acceptance constraint of the poor becomes binding, so $R$ finds it optimal to propose a policy combo that results in higher public good provision but lower consumption to herself, so as to keep entitlements as low as possible. Once $\bar{e} \geq \frac{\Delta}{2}$, the best proposal involves the Samuelson level of public good provision $g^{*}$ and the smallest possible entitlement level and taxes that would induce $P$ to accept the proposal. The highest consumption equality is achieved when $\bar{e}$ is large under a proposer of type $R$ in the last period of the finite horizon game.

Summarizing, the second period choices depend on status quo values of entitlements and taxes. Low existing taxes force poor proposers to provide private consumption allocations which are more equitable and public goods which are closer to the first best. This is because under low $\bar{\tau}$, the opposition has high bargaining power and can veto allocations that would expropriate their type's income significantly in order to generate redistribution. On the other hand, when $R$ is the proposer, higher status quo values of entitlements achieve more equitable allocations instead. By having a relatively high minimum consumption to the poor (as established by existing laws), the rich can only make themselves better off by providing public goods above the levels under discretion. The reason being that high tax cuts can be easily be vetoed by poor agents when $\bar{e}$ is large. In other words, entitlement laws protect the poor against policies preferred by the rich whereas a tax code protects the rich against excessive taxation preferred by the poor. Discretionary spending, in the form of public goods, in our model, serves as a bargaining chip for an incumbent to change the status quo in her favor. This is accepted by the opposition because both types of agents value public goods.

One important remark is in place before we move to the first period. That only one of the elements in $s$ is relevant for each policymaker is not a general result. It only holds in the last period of a finite horizon game when there is no continuation utility. In the infinite horizon model, on the other hand, both status quo values are going to be payoff relevant.

\subsection{First-Period Characterization.}

We now characterize first-period allocations and ask whether a proposer with full discretionary power would find it beneficial to deviate from the solution under discretion- knowing her choices in the first-period will impact her continuation value in the second-period by changing the status quo- - Given the static nature of the solution under discretion (discussed in Section 4.1) a proposer facing $q=1$ would find it optimal to choose the policies under discretion in both periods. There is no gain to introduce a tax code or an entitlement program that would move allocations away from $g^{D}$ and $c^{D}$, as these achieve the highest level of welfare for the proposer at every point in time. This is no longer the case under uncertainty, as the appropriate choice of taxes and entitlements could 'tie the hands' of her successor. By choosing alternative taxes and entitlements today, a proposer can manipulate future decisions through the endogenous status quo channel. More importantly, altering the optimal policy mix today can provide insurance against expropriation in the event that the opposition gains proposal power.

To show this, consider a situation where incumbent $P$ proposes a public good provision allocation $g_{1}$ and policies $\pi_{P, 1}=\left\{\tau_{1}, e_{1}\right\}$. The proposer has discretionary power today but understands that these policies become the status quo next period, $s=\pi_{P, 1}$. The incumbent's maximization problem is 


$$
\begin{gathered}
\max _{\left\{\tau_{1}, e_{1}, g_{1}\right\}} \ln \left(c_{P, 1}\right)+\ln \left(g_{1}\right)+\beta\left\{q V_{P}\left(\pi_{P, 1}\right)+(1-q) W_{P}\left(\pi_{P, 1}\right)\right\} \\
\text { s.t. eqs. (1)and }(3)-(4),
\end{gathered}
$$

where we have used the fact that $s=\pi_{P, 1}$. The value functions $V_{P}\left(\pi_{P, 1}\right)$ and $W_{P}\left(\pi_{P, 1}\right)$ can be obtained by evaluating the solution characterized in Propositions 3 and 4 into the utility in the second period. The continuation utility of proposer $P$ if she stays in power tomorrow is given by

$$
V_{P}\left(\tau_{1}\right)=\left\{\begin{array}{lll}
\ln \left(g^{*}\right)+\ln \left(\frac{Y^{2}-4 \bar{x}\left[y_{R}-\tau_{1}\right]}{2 Y}\right), & \text { if } & \tau_{1}<\frac{\Delta}{2} . \\
\ln \left(y_{R}-\tau_{1}\right)+\ln \left(y_{P}+\tau_{1}-\bar{x}\right), & \text { if } & \tau_{1} \in\left[\frac{\Delta}{2}, \tau_{R}^{D}\right) \\
\ln \left(g^{D}\right)+\ln \left(c_{P, P}^{D}\right), & \text { if } & \tau_{1} \geq \tau_{R}^{D}
\end{array}\right.
$$

This is because only $\tau_{1}$, the level of entitlements received by the opposition, may constrain future decisions when $P$ remains in power. If $R$ becomes next period's proposer, then it is the current entitlement level $e_{1}$ what will constrain $R^{\prime}$ s decisions instead. The continuation utility for $P$ in such case would be

$$
W_{P}\left(e_{1}\right)= \begin{cases}\ln (\bar{x})+\ln \left(g^{D}\right), & \text { if } e_{1}<e_{P}^{D} \\ \ln (\bar{x})+\ln \left(y_{P}+e_{1}\right), & \text { if } e_{1} \in\left[e_{P}^{D}, \frac{\Delta}{2}\right) \\ \ln \left(\frac{2 \bar{x}\left[y_{P}+e_{1}\right]}{Y}\right)+\ln \left(g^{*}\right), & \text { if } \quad e_{1} \geq \frac{\Delta}{2} .\end{cases}
$$

This function is computed by replacing $R$ 's optimal choices on $P^{\prime}$ s utility next period.

Proposer $P$ chooses allocations in the first period to maximize eq. (15), which can be re-written as

$$
\max _{\left\{\tau_{1}, e_{1}\right\}} \ln \left(y_{P}+e_{1}\right)+\ln \left(\tau_{1}-e_{1}\right)+\beta\left\{q V_{P}\left(\tau_{1}\right)+(1-q) W_{P}\left(e_{1}\right)\right\},
$$

subject to the lower bound constraints. We have used eqs. (1)-(3) to write down all the allocations in the first period in terms of policy.

Inspection of the problem above reveals that it is optimal for proposer $P$ to set current taxes as high as possible, $\tau_{1}=y_{R}-\bar{x}$. This maximizes resources in the current period and improves $P^{\prime} \mathrm{s}$ bargaining power tomorrow. The first order condition with respect to $e_{1}$ is

$$
\underbrace{\frac{1}{c_{P, 1}}}_{M U_{c}}-\underbrace{\frac{1}{g_{P, 1}}}_{M U_{g}}=\underbrace{\beta(1-q) \frac{\partial W_{P}\left(e_{1}\right)}{\partial e_{1}}}_{\text {wedge }_{c}>0} .
$$

In the absence of uncertainty (e.g. $q=1$ ), the proposer would set the left hand side of the equation to zero, which achieves the solution under discretion. At that point, the private marginal costs and benefits of entitlements are equated. When $q<1$, the proposer finds it optimal to distort the solution because, by choosing $e_{1}>e_{P}^{D}$ it is possible to affect the status quo inherited by the opposition if group $R$ becomes the proposer next period, therefore increasing her own welfare, $W_{P}\left(e_{1}\right)$, in that state of the world. The solution to the first period allocations under an entitlement rule is characterized in Proposition 5. 
Proposition 5 The unique proposal strategy for incumbent $P$ under an entitlement rule is:

$$
\mathcal{E}_{P, 1}=\frac{2 e_{P}^{D}+\beta(1-q) \tau_{P}^{D}}{2+\beta(1-q)}, \quad \Psi_{P, 1}=\tau_{P}^{D}, \quad \text { and } \quad \mathcal{G}_{P, 1}=\frac{2}{2+\beta(1-q)} g^{D},
$$

with associated allocations

$$
\mathcal{C}_{P, P, 1}=\frac{2(1+\beta(1-q))}{2+\beta(1-q)} c_{P, P}^{D} \quad \text { and } \quad \mathcal{C}_{R, P, 1}=\bar{x} .
$$

Proof. See Appendix 9.7

The solution above determines $s$, and hence the constraint faced by tomorrow's policymaker. Proposer $P$ chooses the maximum level of taxes to the rich today, because this maximizes her bargaining position in the second period if she remains in power. Her preferred level of entitlements, on the other hand, depends on the probability $q$. When $q=1$, she simply sets $\mathcal{E}_{P, 1}=e_{P}^{D}$, which together with $\Psi_{P, 1}=\tau_{P}^{D}$ delivers discretionary levels of private and public good consumption. Under uncertainty, the proposer sets $\mathcal{E}_{P, 1}>e_{P}^{D}$, understanding that this results in too little public good provision today and too much private consumption. This is a current cost because it distorts the allocation relative to discretion. The gain arises in the future: by establishing an overly generous entitlement program today, it forces the opposition to offer a better policy mix tomorrow. By over-spending on entitlement programs, the current proposer ensures a better bargaining position next period.

It is easy to show that if $R$ was the first-period proposer, she would choose taxes and entitlements to favor her own private consumption while sacrificing the provision of public goods. In particular, she would set entitlements to their lowest possible level $\mathcal{E}_{R, 1}=e_{R}^{D}$, in order to ensure maximum bargaining power in case she remains the proposer in the second period. She would adjust taxes trading off current distortions against insurance against future expropriation in response to alternative values of $q$. The resulting allocations are summarized in Corollary 4.

Corollary 4 The unique proposal strategy for incumbent $R$ under an entitlement rule is:

$$
\mathcal{E}_{R, 1}=\bar{x}-y_{P}, \quad \Psi_{R, 1}=\frac{y_{R}+(1+\beta(1-q)) e_{R}^{D}}{2+\beta(1-q)}, \quad \text { and } \quad \mathcal{G}_{R, 1}=\frac{2}{2+\beta(1-q)} g^{D},
$$

with associated allocations

$$
\mathcal{C}_{R, R, 1}=\frac{2(1+\beta(1-q))}{2+\beta(1-q)} c_{R, R}^{D} \quad \text { and } \quad \mathcal{C}_{P, R, 1}=\bar{x} .
$$

Proof. See Appendix 9.8

The symmetry (e.g. $\mathcal{C}_{R, R, 1}=\mathcal{C}_{P, P, 1}$ and $\mathcal{G}_{R, 1}=\mathcal{G}_{P, 1}$ ) arises because we have assumed the two types have equal utility functions and because the bounds on taxes and entitlements imply that both agents face a common minimum consumption level $\bar{x}$. If we had tightened the upper bound on taxes, for example, allowing rich agents a higher minimum level of consumption, her choices would be significantly different from $P^{\prime}$ s in the first period. While this is an interesting case to study, we leave it for future research. The symmetric case eases the exposition of our results. 

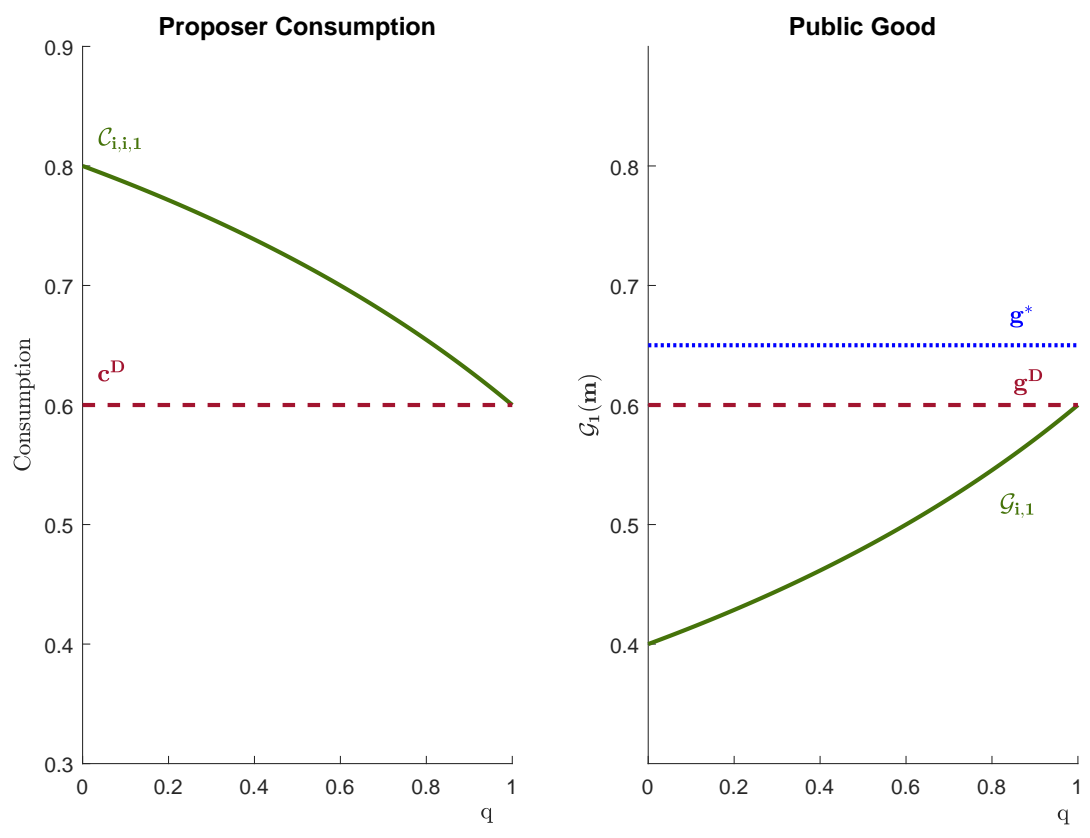

Figure 5: Allocations under Budget Rules as functions of $q$.

The left panel of Figure 5 depicts private consumption allocations in the bargaining equilibrium for proposer $i$ (solid line) and under discretion (dashed line) as functions of $q$, whereas the right panel depicts public good provision in the two cases, together with the Samuelson level $q^{*}$. The figure-which was constructed using the same parameters as Figure 4-illustrates that the proposer has incentives to increase consumption relative to her optimal choice under discretion when $q<1$. As long as she faces uncertainty, the proposer will use taxes or entitlements to ensure consumption above $\bar{x}$ when out of power. This comes at the cost of under-providing public goods (see right panel of the picture) relative to her preferred value of $g$ under certainty. The net benefit derived from distorting the allocations from those under discretion diminishes in $q$, and as a result $\mathcal{C}_{i, i, 1}$ decreases with the probability of retaining proposal power, $q$.

We showed in previous sections that the solution under discretion was inefficient because the proposer was not providing enough public goods. In other words, that the level of public good provision under discretion was below the efficient Samuelson level $g^{*}$. We can see that when $q<1$, both proposer types would choose entitlements and taxes such that $\mathcal{G}_{i, 1}<g^{D}$, indicating that the bargaining equilibrium delivers under-provision of public goods. In addition, total consumption, computed as the sum between the proposer's and the opposition's will be inefficiently large. The degree of inefficiency exacerbates with political uncertainty. In addition to these static sources of inefficiencies, individual consumption changes over time, as it varies with the identity of the proposer. Volatility, hence, is a second form of inefficiency of the political equilibrium which does not necessarily vanish when we move away from discretion.

What are the implications in terms of equity? Interestingly, these budget rules exacerbate inequities in the first period. Incumbent $i$ sets consumption of the opposition to $\bar{x}$, whereas her own consumption is given by $\mathcal{C}_{i, i, 1}>c_{i, i}^{D}$. As a result, the consumption gap is larger than the one under discretion for $q<1$ and increases with higher political turnover. In the second period, the budget rule reduces the consumption gap in expectation. This is because the incumbent can actually use her first-mover advantage amid a favorable starting point to lock the society in an equilibrium 
that favors her. She chooses policy in order to minimize the degree of expropriation of the other party by setting a status quo which ensures consumption tomorrow to exceed $\bar{x}$.

As we mentioned in the introduction, Bowen, Chen, and Eraslan (2014) showed that introducing mandatory spending rules (on pure public goods) could restore Pareto efficiency. The previous discussion makes it clear that inefficiencies remain in our environment after budget rules that govern private consumption are introduced. It is worth asking, however, whether their introduction generates a Pareto improvement nonetheless. Unfortunately, the answer is that this is not always the case. To see this, consider a stark example where $P$ is the incumbent in the first period and $R$ is the incumbent in the second period (e.g. under $q=0$ ). The following lemma shows that $R$ individuals are worse off when budget rules are introduced.

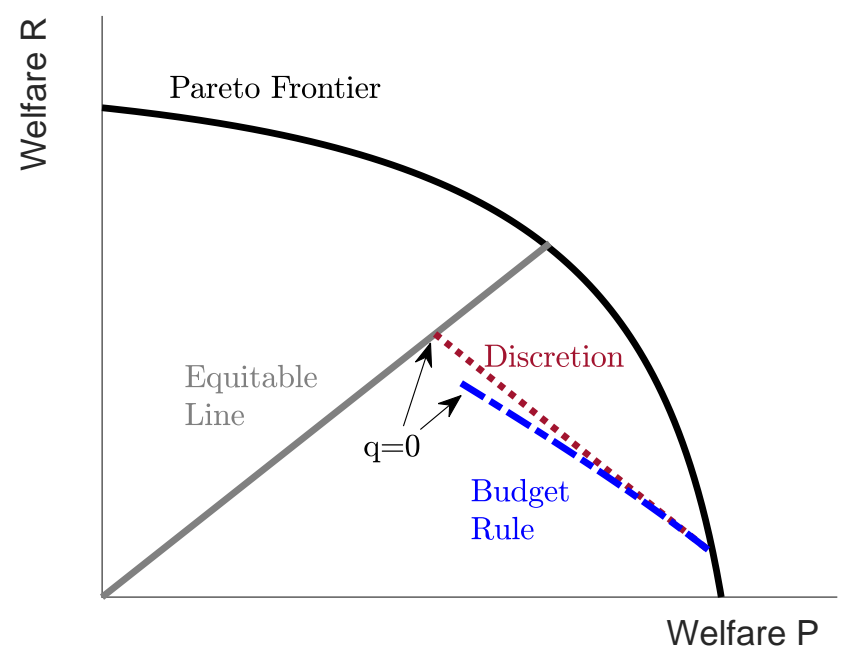

Figure 6: Adopting a Budget Rule from Discretion (P in power) for $q \in[0,1]$

Lemma 1. Let $q=0$ and assume $P$ is in power in period 1 . As $x \rightarrow 0$, group $R$ is worse off with budget rules than with discretion.

Proof. See Appendix 9.9

The example highlights that budget rules do not necessarily lead to Pareto improvements. In Figure 6 we show, numerically, that this is also the case for $q<1$ and $\bar{x}>0$. In particular, we have used $\bar{x}=0.1$. Assuming that $P$ is the proposer in the first period, we plot the lifetime welfare pairs under budget rules (dashed-blue line). While having a budget rule is clearly better for the proposer, the opposition is worse off: the dashed-blue line is at or below the discretion dottedgarnet line. Moreover, the resulting allocations are not only less efficient than discretion (e.g. further away from the Pareto Frontier) but also less equitable (e.g. further away from the Equity line). This is clearest at the point where $q=0$, where parties alternate in power deterministically.

\section{Infinite Horizon Model}

The analysis of the two-period case illustrates how the proposer can strategically use budget rules to position herself advantageously if the opposition were to gain proposal power in the future. A 
shortcoming of that analysis is that it was made under the extreme assumption that the proposer in period 1 is completely unconstrained. She could manipulate the status quo freely because she was not subject to a binding status quo to begin with. In addition, because the economy ended in the second period, the incumbent did not need to consider the reaction of the opposition to the continuation of the game.

In this section, we relax these assumptions by considering an arbitrary initial status quo and allowing the economy to have an infinitely large number of periods. By doing so, we can also study the dynamic behavior of private and public consumption and the welfare implications of budget rules in the long run.

\subsection{Quantitative Analysis}

There is no analytical solution to the proposer's problem in the infinite horizon model. The main reason, and in contrast to most of papers in the bargaining literature, is that we consider riskaverse agents (in both, private and public consumption). Our analysis from now on is, thus, numerical.

We consider an annual model where $Y_{P}=0.1$ and $Y_{R}=1.2$. Utility is logarithmic, $u(x)=\ln x$. The discount factor is set to $\beta=0.96$, consistent with a $4 \%$ interest rate, implying a standard value for the degree of impatience in the literature. The probability of retaining proposal power is $q=$ 0.5 in our benchmark case, implying no persistence in proposer status. This assumption is relaxed in Section 7.6, where allow for alternative turnover risk values. The minimum consumption levels are set to $\bar{x}_{c}=\bar{x}_{g} \equiv \bar{x}=0.1$, as in the two period model. ${ }^{12}$

The next subsection describes our computational strategy in detail. A reader who is not interesting in this can skip to Section 7.3 for a discussion of our findings without loss of continuity.

\subsection{Computation}

We follow the dynamic public finance literature and compute the MPE using the primal approach, where the political equilibrium is re-written (and characterized) in terms of allocations. The transformation, which involves substituting away fiscal policy variables, allows us to reduce the dimensionality of the problem: only a subset of policy functions needs to be computed (e.g. those for private and public consumption). Fiscal policy functions (e.g., taxes and entitlements), can be subsequently backed out using the agents' budget constraints. The first step in doing this transformation involves noticing that the budget constraints eqs. (2) and (3) establish a linear relationship between consumptions $\left\{c_{P}, c_{R}\right\}$ and fiscal policies $\{\tau, e\}$. This implies that, in the transformed problem, we could think of the incumbent as proposing allocations $g$ and $\pi_{P}=\left\{c_{P}, c_{R}\right\}$ and the bargaining process following a protocol analogous to the one described earlier in this paper. If this proposal were rejected, past values of consumption of the rich and poor would remain in effect, thus capturing the inability of the current proposer to change the tax code and the entitlement programs. In terms of writing the problem recursively, this would mean that instead of keeping track of status-quo values $s=\{\bar{e}, \bar{\tau}\}$, the relevant state space would be given by past values of consumption of the rich and the poor: $s=\left\{\bar{c}_{P}, \bar{c}_{R}\right\}$. In addition, we need to make sure the set of constraints in eq. (4) are satisfied in the transformed problem. These constraints imply that the consumption of each agent $i \in\{R, P\}$ cannot be lower than $\bar{x}$, or $c_{i} \geq \bar{x}$. Finally, the government

\footnotetext{
${ }^{12}$ This choice is not without loss of generality. The larger the value of $\bar{x}$, the less important budget rules will be for welfare. At the other extreme, as $\bar{x} \rightarrow 0$, almost any proposal is accepted by the opposition because, due to the logarithmic utility function assumption, not reaching an agreement becomes arbitrarily costly.
} 
constraint eq. (1) together with the consumer budget constraints imply that $g$ is subject to the resource constraint defined in eq. (5).

Given a proposal $\pi_{P}=\left\{c_{P}, c_{R}\right\}$, the transformed problem of a type- $P$ proposer can be written as

$$
\max _{\left\{c_{P}, c_{R}, g\right\}} u\left(c_{P}\right)+u(g)+\beta\left\{q V_{P}\left(\pi_{P}\right)+(1-q) W_{P}\left(\pi_{P}\right)\right\}
$$

s.t. eq. (5), the lower bounds $c_{P}, c_{R}, g \geq \bar{x}$, and the acceptance constraint

$$
\begin{gathered}
u\left(c_{R}\right)+u(g)+\beta\left\{(1-q) V_{R}\left(\pi_{P}\right)+q W_{R}\left(\pi_{P}\right)\right\} \geq \\
u\left(\bar{c}_{R}\right)+u(\bar{x})+\beta\left\{(1-q) V_{R}(s)+q W_{R}(s)\right\},
\end{gathered}
$$

where the state is given by $s=\left\{\bar{c}_{P}, \bar{c}_{R}\right\}$.

Taking advantage of symmetry, the problem can be further simplified, as discussed in our Computational Appendix 10. Despite of all these simplifications, computational problem arise. A well-known issue in dynamic legislative bargaining games with endogenous status quo is that standard algorithms are not always successful in computing Markov-perfect equilibria. This paper is no exception, as standard value-function iteration procedures do not converge for arbitrary parameterizations of the model. It is worth noticing that the convergence problems are not caused by the bounds of taxes and entitlement or the specific form of the utility function. We have experimented with quadratic utility and no minimum consumption and the issue remains (details available upon request). The fact that the computation of models in this class is notoriously challenging has been documented by Duggan and Kalandrakis (2012), Martin (2009), Chatterjee and Eyigungor (2012), and others. A common strategy, also adopted here, is to slightly perturb the choices of the proposing agent through the introduction of small, independent and identically distributed shocks. These shocks may apply to fundamentals, as in Chatterjee and Eyigungor (2012), or to the agent's payoff directly, as in Eyigungor and Chatterjee (2019) or Sanchez et al. (2018). We follow Gordon (2019) and use the functional forms and assumptions employed with discrete choice methods. The resulting randomization over options with payoff of comparable value greatly eases the computation of the model, induces smooth value functions and policy functions, and induces near-monotone convergence via standard value function iteration ${ }^{13}$. Appendix 10 documents the model augmented with taste shocks and our solution algorithm.

\subsection{Policy Rules in the Bargaining Equilibrium}

There are two relevant states in the Markov-Perfect endogenous bargaining equilibrium, namely last period's taxes $\bar{\tau}$ and entitlements $\bar{e}$. In the two-period model, only one of them was relevant for the proposer: proposer $P$ cared about taxes to the rich whereas proposer $R$ cared about entitlements, because these determined the outside option for the opposition. In the infinite horizon model, on the other hand, both states are relevant when choosing a proposal. To fix ideas, suppose that $P$ is the incumbent. The level of taxes established in the code matters because it directly affects how likely the opposition is to accept a reform (as in the two-period example). The value of $\bar{e}$ is also important because, if the proposal is rejected, $\bar{e}$ determines next period's status quo. This, in turn, affects $P^{\prime}$ s bargaining power if $R$ were to become the proposer tomorrow. Through

\footnotetext{
${ }^{13}$ The method requires the introduction of a parameter governing the importance of these taste shocks for the agent's behavior. We set this parameter to the smallest value consistent with convergence within 1,000 iterations, at $\rho=5 e^{-4}$.
} 
continuation utilities, then, $\bar{e}$ affects today's decisions by proposer $P$ (which did not happen in the finite horizon example). To make the analysis cleaner, we first analyze policy rules as functions of status-quo taxes fixing $\bar{e}$, and then let status-quo entitlements vary while fixing taxes.
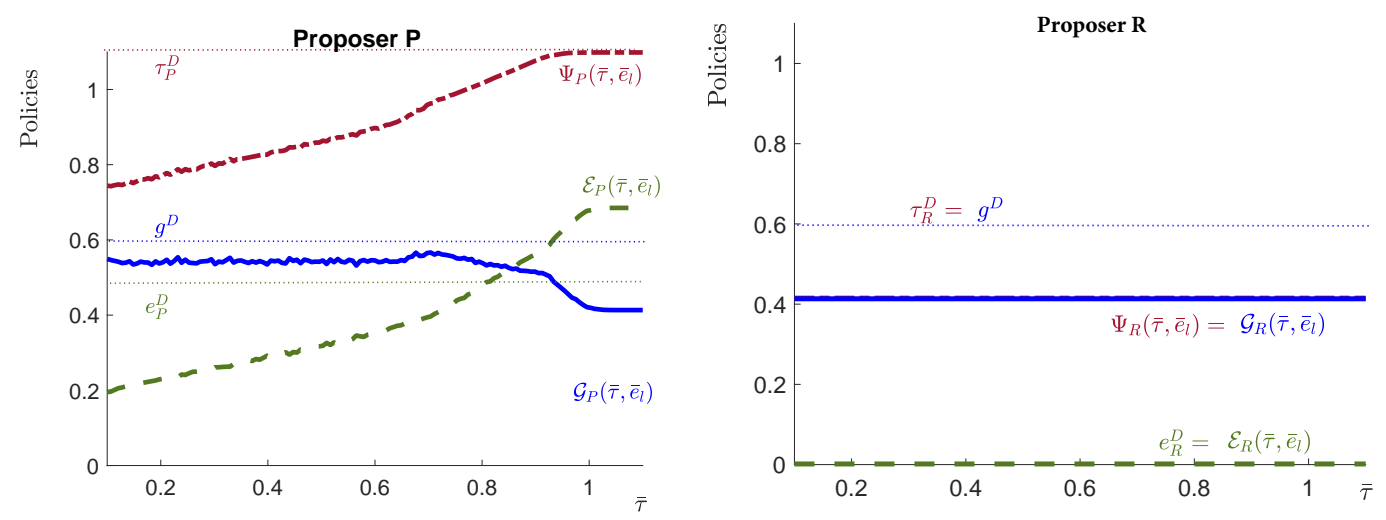

Figure 7: Policy functions for P (left) and R (right) as functions of $\bar{\tau}$ (fixing $\bar{e}_{l}=0$ ).

The left panel of Figure 7 depicts $P^{\prime}$ s equilibrium policy rules as functions of $\bar{\tau}$, fixing entitlements at their minimum possible value: $\bar{e}_{l}=0$. As in the two-period model, taxes (dot-dashed garnet line) and entitlements (dashed green line) are increasing in the status-quo level of taxes $\bar{\tau}$, whereas public good provision (solid blue line) declines with it (compare this to Figure 4). When $\bar{\tau}$ is close to the maximum, $P$ sets taxes at their maximum feasible level and uses its proceeds to finance extremely high entitlement levels—so that her own private consumption is large-and relatively low levels of public goods. A key difference with the two-period model, however, is that for $\bar{\tau}>\tau_{R}^{D}=0.6$, entitlements are significantly above their value under discretion $\mathcal{E}_{P}>e_{P}^{D}$ whereas public good provision is significantly below it, $\mathcal{G}_{P}<g^{D}$. This is a result of the effect of continuation values on current choices. Incumbent $P$ sets a large entitlement program today in order to make it difficult for the opposition to reduce it in the future. As a result, there is overprovision of private consumption (through entitlements) and under-provision of public goods, even relative to discretion. When $\bar{\tau}$ is low, $P^{\prime}$ s bargaining power is very limited (remember that entitlements are set at zero at the outset of the period), making such choices unfeasible. A poor proposer is forced to offer more public goods and a smaller entitlement program than she would like to, because anything else would be rejected by the opposition. Overall, we can see that public good provision is smaller than under discretion in the legislative bargaining equilibrium. The right hand side of Figure 7 shows the policy rules of a rich incumbent that starts the period with $\bar{e}_{l}=0$. Clearly, $R$ has no incentives to start an entitlement program and chooses $\mathcal{E}_{R}=0$ for any value of $\bar{\tau}$. Because of the effect of potentially losing elections in the future, she limits the size of the government by choosing lower taxes and public good provision than under discretion. This is an attempt to tie the hands of a potential poor successor who would like to expand the entitlement program.

In Figure 8, we keep status-quo taxes fixed at their maximum feasible level $\bar{\tau}_{h}=1.1$ and vary potential status-quo variables for $\bar{e}$. The policy rules of incumbent $P$, shown in the left panel, are constant in $\bar{e}$. Her bargaining power is largest when taxes are at the upper bound $\bar{\tau}_{h}$, similarly to the scenario for $R$ when entitlements were at the lower bound $\bar{e}_{l}=0$ (in the previous figure). However, $P$ 's choices are very different: She keeps taxes high, the entitlement program above what she would under discretion, and the provision of public goods below $g^{D}$. This is all resulting from the effect of continuation utility once the model has more than two periods. Proposer $P$ is willing 

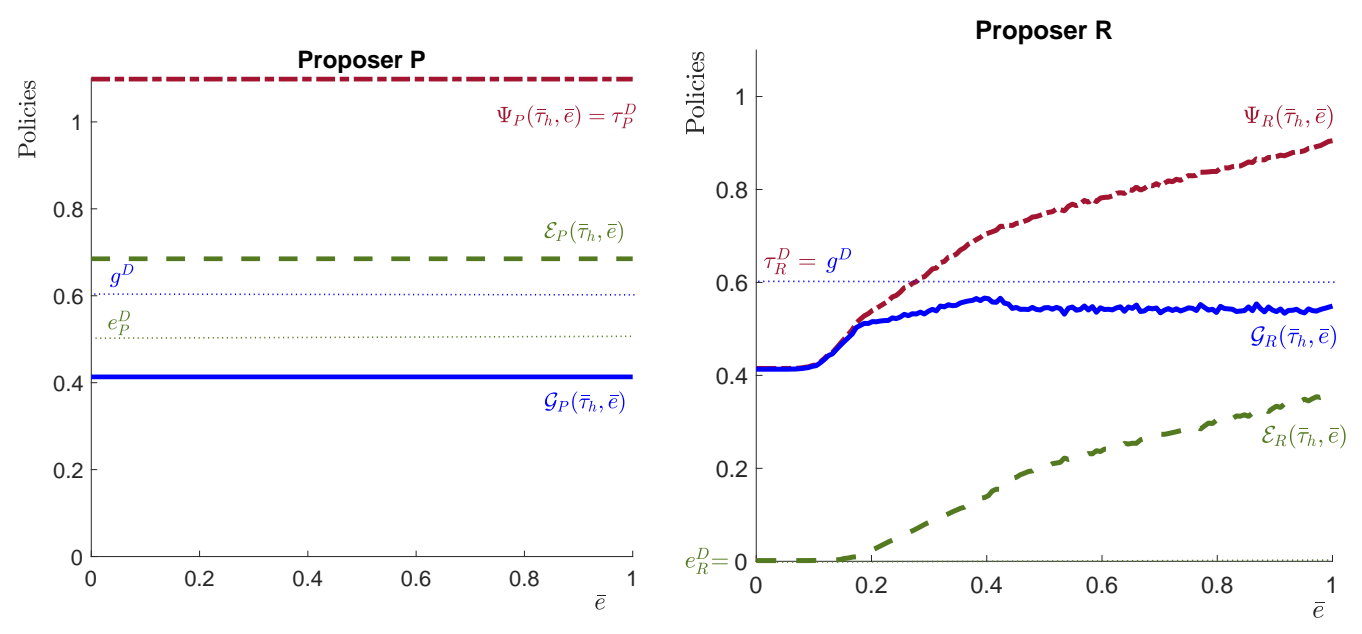

Figure 8: Policy functions for P (left) and R (right) as functions of $\bar{e}$ (fixing $\bar{\tau}_{h}=1.1$ ).

to distort her fiscal policy choices to keep entitlements high in the event of losing proposal power next period. This strategy insures her against a slashing of such programs by the opposition, and establishes a high lower bar for her future consumption. The right panel shows $R^{\prime}$ s policy variables for the same set of states. Given that status-quo taxes are high (at their maximum values, actually), when entitlements are low, $R$ finds it beneficial to propose a significant tax-cut. By keeping entitlements at zero, $R$ can decrease taxes even below their value under discretion; this can be seen by the fact that the garnet line for $\Psi_{R}$ lies below the dashed line for $\tau_{R}^{D}$ for $\bar{e}$ close to zero. Recall that taxing at $\tau_{R}^{D}$ and using this to finance $g^{D}$ is optimal under discretion, and it is actually what $R$ would do in the two-period model when the acceptance constraint does not bind (e.g. for small $\bar{e}$ ). In an environment with a longer horizon, however, a rich proposer is willing to distort her choices away from discretion in order to ensure herself a better barging position in the future. By keeping taxes very low, it can tie the hands of a successor from the $P$ group who wants a larger government size. As the status-quo value of entitlements grows, $R$ can only slash these programs by providing more public goods, and it chooses to do so for intermediate values of $\bar{e}$.

\subsection{Evolution of Policy}

The analysis above illustrates that budget rules that make taxes and entitlement programs difficult to change affect a proposers' incentives dynamically. By forcing changes to have a bipartisan support, these rules restrict policymakers' choices, potentially smoothing their evolution over time. Because they have consequences in the future, the strategic incentives may, however, significantly distort the optimal mix between private and public goods. In this subsection, we conduct a series of simulations to further study how policies and allocations evolve over time.

When $P$ is in power a long time: We first consider a scenario where proposer $P$ starts period 0 with status-quo taxes $\bar{\tau}=0.4$ and $\bar{e}=0.1$, inherited from period -1 . We assume that proposer $P$ make choices under uncertainty, but the realizations of the shock are such that there is no turnover, so $P$ happens to make proposals in all subsequent periods. Policies are shown over time on the left panel of Figure 9, whereas the right panel depicts allocations. Because the status quo value of $e$ in period 0 is lower than the value desired by the proposer, the only way in which $P$ can expand 

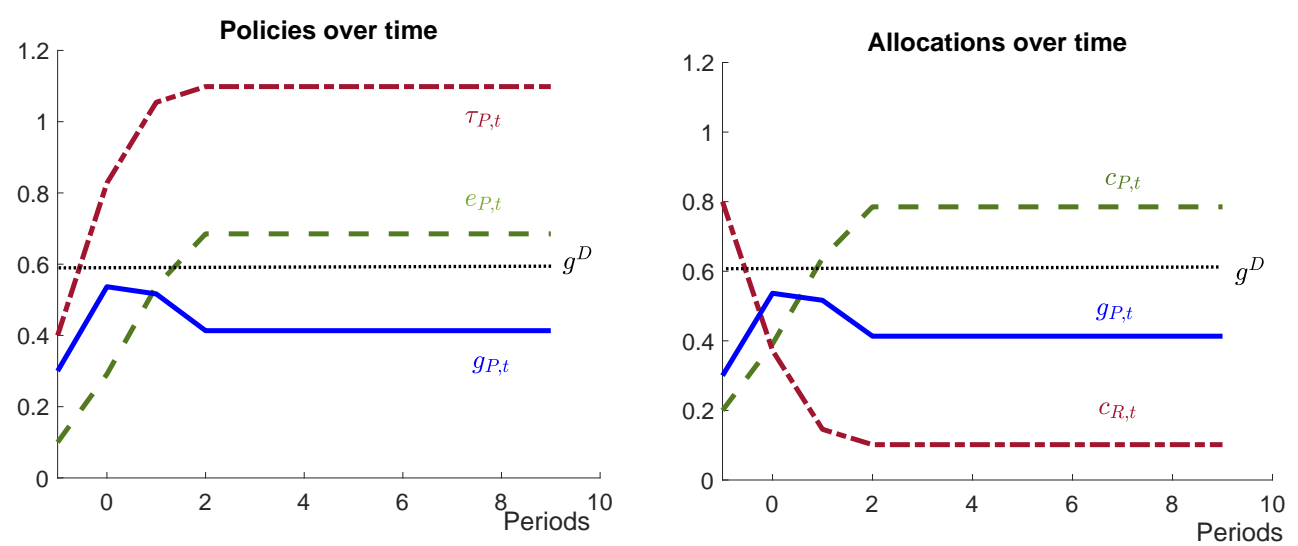

Figure 9: Taxes and entitlements under proposer $P$.

the size of the entitlement program is by offering $R$ more public goods (blue solid line, left panel), which of course involves an increase in taxes (dot-dashed garnet line, left panel). The rich are willing to accept this because, even though they consume fewer private goods in period 0 (dotdashed garnet line, right panel), the provision of public goods increases. The poor are willing to propose this because they also value $g$. This temporarily decreases inequality and moves $g$ closer to the efficient Samuelson level $g^{*}$. To the extent that $P$ remains in power, she will slowly expand the entitlement program - and hence her own consumption of private goods - both dashed green lines), through rises in taxes. Eventually, $P$ will be able to secure herself a good enough bargaining position (through high $\bar{e}$ ) to start reducing $g$ and keep high taxes in order to finance increases in $e$. If $P$ is in power long enough, she would reach a steady-state level of private consumption, which is significantly higher than what she would choose under discretion. In that new steady state public good provision is inefficient and there is a high degree of ex-post income inequality, as seen by the distance between the two consumption levels (which reflect after-tax income).
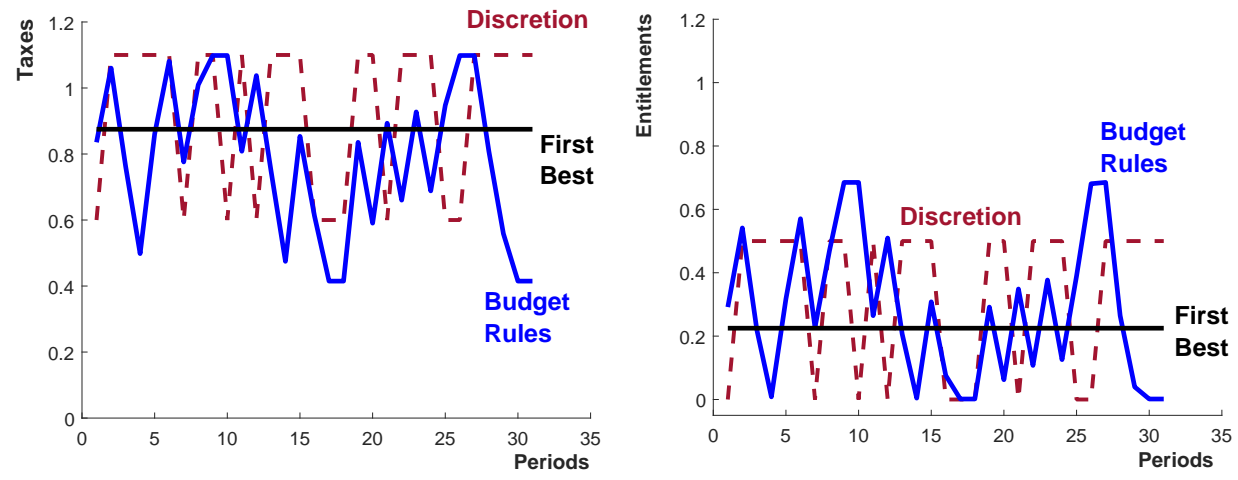

Figure 10: Taxes and entitlements over time (power alternation).

When $P$ and $R$ alternate in power: The economy would only reach a steady state if one of the parties were in power forever. Because the proposer changes stochastically, the direction of policy does as well. In Figure 10, we show the time-series for a 30-period sample simulation of taxes 
(solid blue, left panel) and entitlements (solid blue, right panel). The rich, when in power, introduce tax-cuts and slash entitlement programs in order to increase their own private consumption. The poor want to expand the size of the government by increasing both, taxes and entitlements. This changes inequality over time, as illustrated in Figure 11, depicting the share of income of the poor over time. Without transfers, the poor only have access to $10 \%$ of total income (recall that $y_{P}=0.1$ in our example, roughly $7.7 \%$ of total income). Under budget rules, they are able to significantly increase their share of income over time.

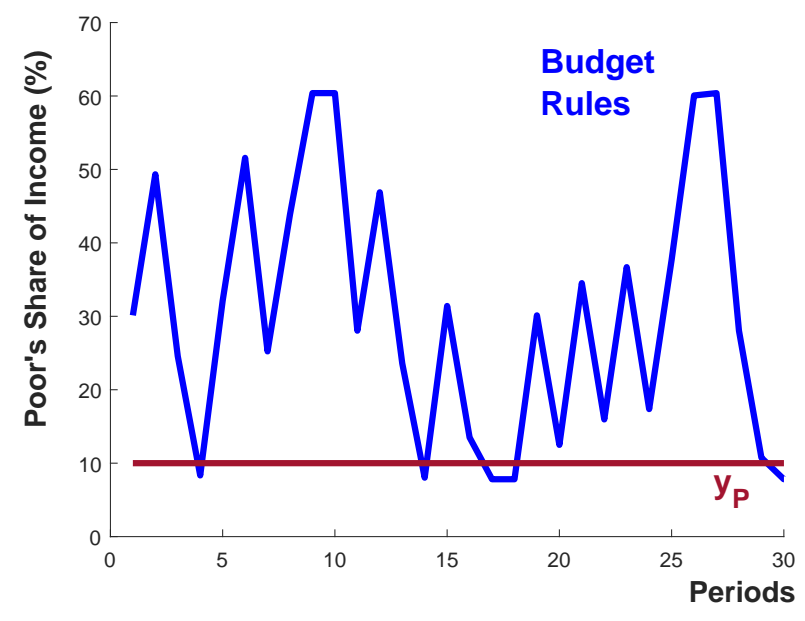

Figure 11: Share of income of the poor over time.

In Figure 10, we also depict the simulation under discretion (dashed garnet line) and the set of policies that would decentralize the first best characterized in eq. (9) (black line). First, note that a utilitarian planner would tax the rich and give entitlements to the poor in order to equate their consumptions (making inequality equal to zero at all times). The first best policies are, however, constant over time. As we discussed in previous sections, under discretion policies alternate between those preferred by each type. We can see in the figure that they are extremely volatile and not very persistent. Finally, with budget rules, sequences are smoother (changes take longer to materialize), but they can end up at more extreme values. The budget rule (blue) line is sometimes above the discretion (garnet) line. Consumption allocations have similar cyclical properties due to the assumption of constant endowments. Their long-run distributions are characterized next.

\subsection{The long-run distribution}

Over time, the economy reaches an ergodic set determining a range in which policy fluctuates forever-after. Because of the dimensionality of the state space, it is not possible to characterize the stationary equilibrium using policy functions (something we could do with only one state variable). To compute the ergodic set, we simulated the economy for 1,000,000 periods, and eliminated the first 1,000 periods. It is worth noticing that the economy converges to the same set regardless of initial conditions in our benchmark economy.

Figure 12 depicts a scatter plot of taxes and entitlement pairs for each period in the simulation (marked blue circles), together with the pairs that would be obtained under discretion for each type of proposer (marked with a garnet square). Policies span a significant portion of the 


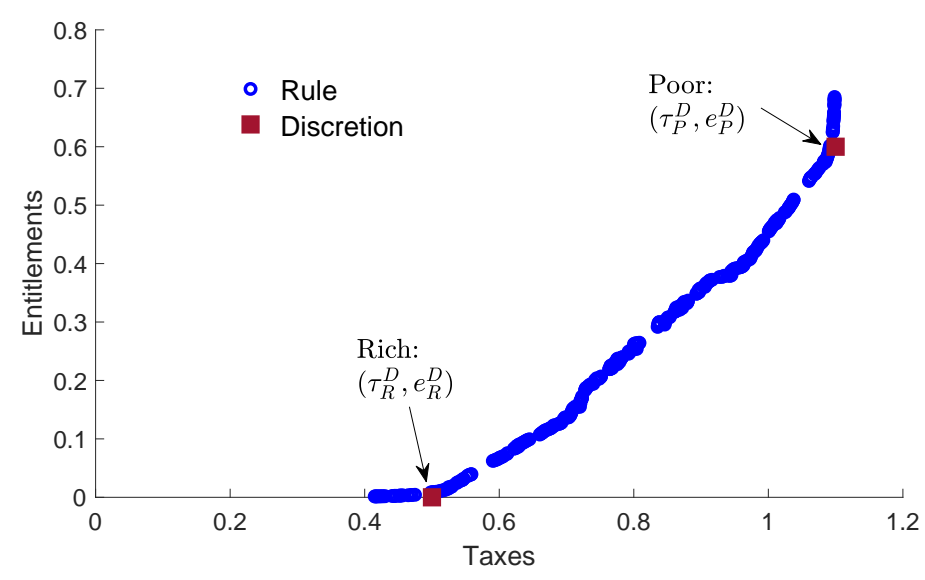

Figure 12: Scatter plot of private consumption pairs in the simulation.

state-space in the bargaining solution, whereas they jump between only two values under discretion. This implies that the evolution of policy (and hence, of private and public consumption) is smoother when budget rules are in place. This is consistent with the long-run moments reported in the last column of Table 1, where we see that the autocorrelation coefficients of fiscal policies and private consumption levels are around 0.5 , whereas they are basically zero under discretion. Public good provision, on the other hand, is more volatile under budget rules. Policymakers are willing to distort the time-path of private goods in order to reduce the volatility of private consumption, which is the good most expropriated when policies are determined in the absence of rules and, therefore, is the good that has higher demand for insurance against expropriation. This can be seen by comparing the coefficients of variation of the discretion versus budget rules' columns.

Interestingly, taxes are smaller than the level needed to decentralize the first best, but entitlements are larger. As a result, there is over-provision of private goods and under-provision of public goods in the bargaining equilibrium (compare the average value of $c$ and $g$ in the table). This finding is consistent with our discussion in the two-period model. Despite this inefficiency, these allocations are more equitable. The Gini coefficient, computed for after-tax income, is on average 0.36 under discretion, whereas it is 0.23 when budget rules are in place, highlighting the importance of this set of budget rules to promote equity by preventing insurance against expropriation.

\subsection{Rules vs Discretion}

It is worth asking whether introducing budget rules would result in a Pareto improvement relative to the discretionary case. The answer, as we show next, depends critically on two factors. The first one is the initial status quo, determined by the identity of the party in power the period before the rule is introduced. This is because initial conditions affect the relative bargaining power of the two parties once budget rules are in place, giving one of them a 'first mover' advantage. The second one is the degree of political persistence. This is because the higher the value of $q$ is, the longer a given party enjoys her first mover advantage.

We consider a situation where the economy has been under discretion until period $T$, and before period $T+1$ starts, budget rules are introduced unexpectedly to be in place from that point onwards. In order to evaluate the welfare implications of this change from period $T+1$ into the 


\begin{tabular}{lrrr}
\hline & Optimal & Discretion & Budget Rules \\
\hline Taxes $(\tau)$ & & & \\
Mean & 0.88 & 0.84 & 0.79 \\
Coef. of Var. & 0.0 & 0.29 & 0.31 \\
Autocorrelation & 1.0 & 0.005 & 0.51 \\
Entitlements $(e)$ & & & \\
Mean & 0.23 & 0.24 & 0.30 \\
Coef. of Var. & 0.0 & 1.02 & 0.83 \\
Autocorrelation & 1.0 & 0.005 & 0.51 \\
Private Goods Consumption $\left(c_{P}\right)$ & & \\
Mean & 0.33 & 0.34 & 0.41 \\
Coef. of Var. & 0.0 & 0.73 & 0.62 \\
Autocorrelation & 1.0 & 0.005 & 0.51 \\
Public Goods (g) & & & \\
Mean & 0.65 & 0.60 & 0.49 \\
Coef. of Var. & 0.0 & 0.0 & 0.12 \\
Autocorrelation & 1.0 & 1.0 & 0.21 \\
& & & \\
\hline
\end{tabular}

Table 1: Moments of the Ergodic Distribution, By Regime

future, it is important to specify: (i) who is the proposer at $T+1$ and (ii) who was the proposer in $T$. The identity of the proposer in the previous period is important because it determines the status quo values $\bar{\tau}$ and $\bar{e}$. We assume that $P$ is the proposer at $T+1$ and consider the two possible values for the initial status quo, namely $s_{P}=\left(\tau_{P}^{D}, e_{P}^{D}\right)$ and $s_{R}=\left(\tau_{R}^{D}, e_{R}^{D}\right)$. The first one corresponds to the situation where $P$ was also in power in $T$, whereas in the second one we assume that $R$ was in power instead.

In the left panel of Figure 13 we plot welfare pairs for the two groups under discretion (marked with a garnet diamond) and the bargaining solution (marked with blue squares) assuming that party $P$ is the proposer in the two scenarios, and that the initial status quo is given by $s_{P}$. Each blue square corresponds to a different value of $q \in[0.5,1]$, with arrows indicating welfare combinations in our benchmark case of no incumbency advantage. We also plot the Pareto Frontier (in black) and the Equitable Line (in gray) for reference. Introducing the budget rule when $q=0.5$ improves efficiency (making welfare closer to the Pareto Frontier) and generates a Pareto improvement. The gain for $P$ is significant, whereas $R$ 's welfare gain is marginal (these are depicted on the right panel of Figure 13). This happens because the initial condition is beneficial for proposer $P$ at the time of introducing the budget rules. Recall that $s_{P}$ involves high taxes and generous transfers, so $R^{\prime} s$ bargaining power is limited in this case. The allocation is less equitable (e.g. it is further from the Equitable Line). The efficiency gains dominate the equity losses, resulting in an overall welfare gain for the utilitarian planner.

The welfare gains of adopting budget rules are, however, decreasing in $q$. For proposer $P$, they are positive for all values of $q$ considered, implying that under this scenario $P$ is always better off with rules than under discretion. That is not the case for the opposition, as $R$-agents are worse off for $\bar{q} \geq 0.53$. When $q$ is large, but still smaller than 1 , the proposer knows that with a very small probability it can be replaced by $R$, who will slowly slash entitlement programs. Because 
of persistence, $R$ will herself remain in power long enough to get close to her preferred discretion allocations, implying very small consumption levels for $P$. In anticipation of that unlikely, but unfortunate state of the world, $P$ chooses a very large level of taxes and entitlements, at the expense of public good provision. This choices keep R's consumption close to the lower bound $\bar{x}$. Under discretion, $R$ can obtain the same (low) value of private consumption, but a much larger $g$. Because of this, discretion would be preferable for $R$. In other words, imposing budget rules in an environment where policymakers remain in power for long periods of time can be welfare-reducing for the opposition due to distortions in discretionary spending (e.g., public good g). Hence, consistently with the two-period model example, introducing a budget rule does not always lead to a Pareto Improvement.
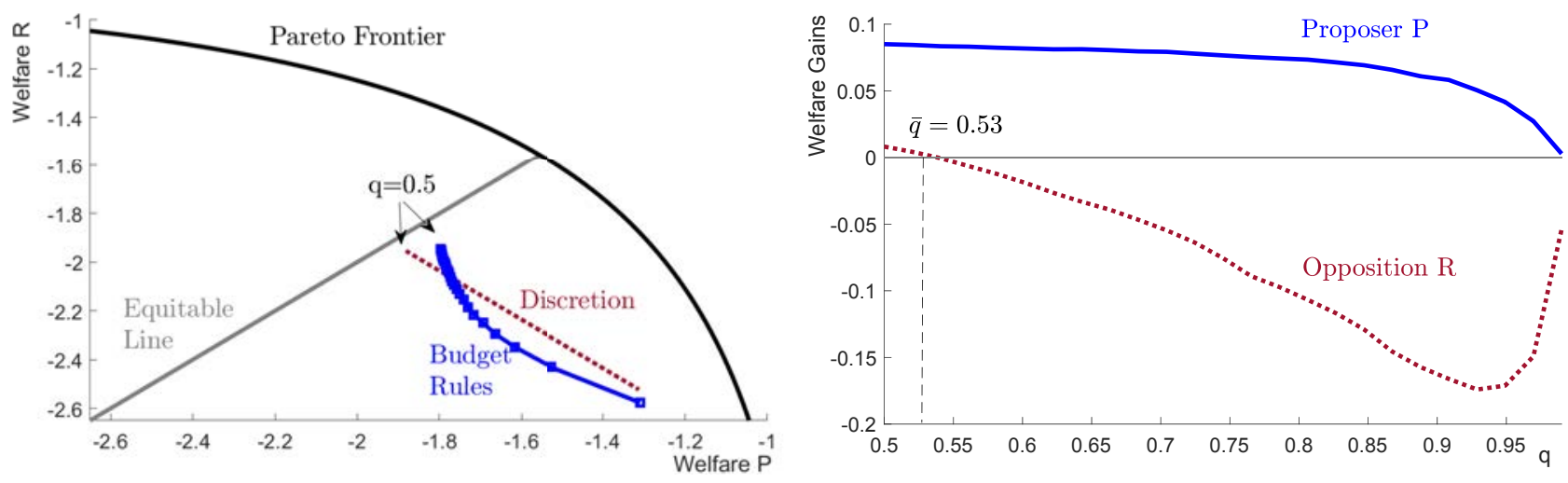

Figure 13: Budget rules and political persistence for $s_{0}=\left(\tau_{P}^{D}, e_{P}^{D}\right)$.

In addition, it is worth noticing that introducing these rules from a starting point with discretion does not necessarily improve equity. The reason being that the policymaker introducing the reform can set up the tax code and the entitlement program in such a way that it benefits her. This 'first mover' advantage only grows with the degree of persistence. ${ }^{14}$
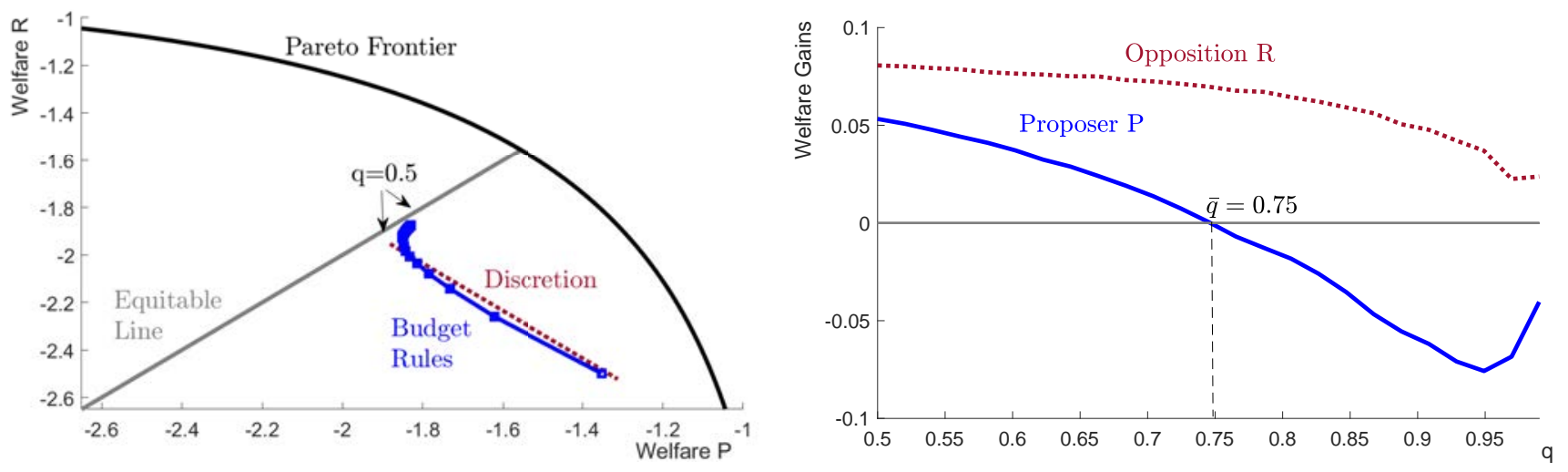

Figure 14: Budget rules and political persistence for $s_{R}=\left(\tau_{R}^{D}, e_{R}^{D}\right)$.

In Figure 14, we fix the initial state to be $s_{R}=\left(\tau_{R}^{D}, e_{R}^{D}\right)$. That is, we consider a situation where

\footnotetext{
${ }^{14}$ Note that in this experiment we only set the initial status quo at the discretion level $s_{P}$. This limits $T+1$ choices but $P$, through the acceptance constraint, but does not force $P$ to actually propose $s_{P}$. Generically, $P$ will propose policies which are more extreme than those under discretion to take advantage of her proposal power.
} 
$P$ is the proposer today, but $R$ was the proposer in the previous period. This situation is clearly more advantageous for the opposition $R$, who starts period $T+1$ at a much stronger bargaining position. Now, for the respondent it is always beneficial to implement budget rules, as seen in the right hand side of the panel, where the dashed garnet line-representing gains from discretion for $R$-is always greater than 0 . For the proposer, on the other hand, the rule involves lower welfare than discretion for any $q \geq 0.75$.

\subsection{Institutional Reform}

The analysis above shows that budget rules do not necessarily generate a Pareto improvement. Because there are winners and losers, it is not clear that implementing them would be feasible when policymakers need to agree to do so. If the opposition is worse off, it would never support introducing the rules in the first place. If the proposer is worse off, it would never bring them up to the bargaining table.

In this section, we consider a situation where both parties have to agree on whether to introduce a budget rule through a once-and-for-all bargaining process. That is, at time $T$, a party is chosen at random and proposes: (i) the introduction of budget rules and (ii) fiscal policy for the current period ( $\tau$ and $e$ ). The other party may accept or reject this proposal. If accepted, taxes and entitlements become the status quo for the following period, $T+1$, and the game follows the same bargaining protocol as described in the previous sections. If the proposal is rejected, the economy continues under discretion forever after. There are two important differences between this problem and the ones solved before. First, the proposer can strategically choose the initial status quo (before, we were considering $s_{P}$ or $s_{R}$, which were the policies under discretion). Second, the proposer is constrained to make both herself and the opposition at least as well off as under discretion.

Suppose that $P$ is selected to make the proposal in period $T$. Her optimization problem is then

$$
\max _{\pi_{P}=\{\tau, e\}} \ln \left(y_{P}+e\right)+\ln (\tau-e)+\beta\left\{q V_{P}\left(\pi_{P}\right)+(1-q) W_{P}\left(\pi_{P}\right)\right\},
$$

subject to eq. (1), eq. (4), the reform acceptance constraint

$$
\ln \left(y_{R}-\tau\right)+\ln (\tau-e)+\beta\left\{(1-q) V_{R}\left(\pi_{P}\right)+q W_{R}\left(\pi_{P}\right)\right\} \geq V_{R}^{D} .
$$

an incentive compatibility constraint

$$
\ln \left(y_{P}+e\right)+\ln (\tau-e)+\beta\left\{q V_{P}\left(\pi_{P}\right)+(1-q) W_{P}\left(\pi_{P}\right)\right\} \geq V_{P}^{D} .
$$

Equation (18) establishes that in order for the proposal $\pi_{P}$ to be accepted by party $R$, it needs to deliver at least as much welfare as would be attained under discretion $V_{R}^{D}$ (where the latter is defined by eq. 29). Equation (19) ensures that adopting the budget rule is beneficial for the proposer (e.g. that her welfare is higher than discretion $V_{P}^{D}$ ). Figure 15 illustrates the regions in the state-space for all $(\tau, e)$-pairs satisfying these two conditions. The orange area represents policy pairs where $R$ is better off, so that eq. (18) holds, the blue area is the set of policy choices where eq. (19) holds, and the darker purple are is the region where both hold at the same time (e.g. where the proposal generates a Pareto improvement). Note that $R$ would agree to a reform that introduces a small government, with low taxes and entitlement generosity, whereas $P$ prefers relatively larger welfare programs. The discretion points $s_{R}$ and $s_{P}$ are depicted with black circles. Proposer $P$ would rather stay under discretion than reforming the system under $R^{\prime}$ s discretion policies $\tau_{R}^{D}$ and 


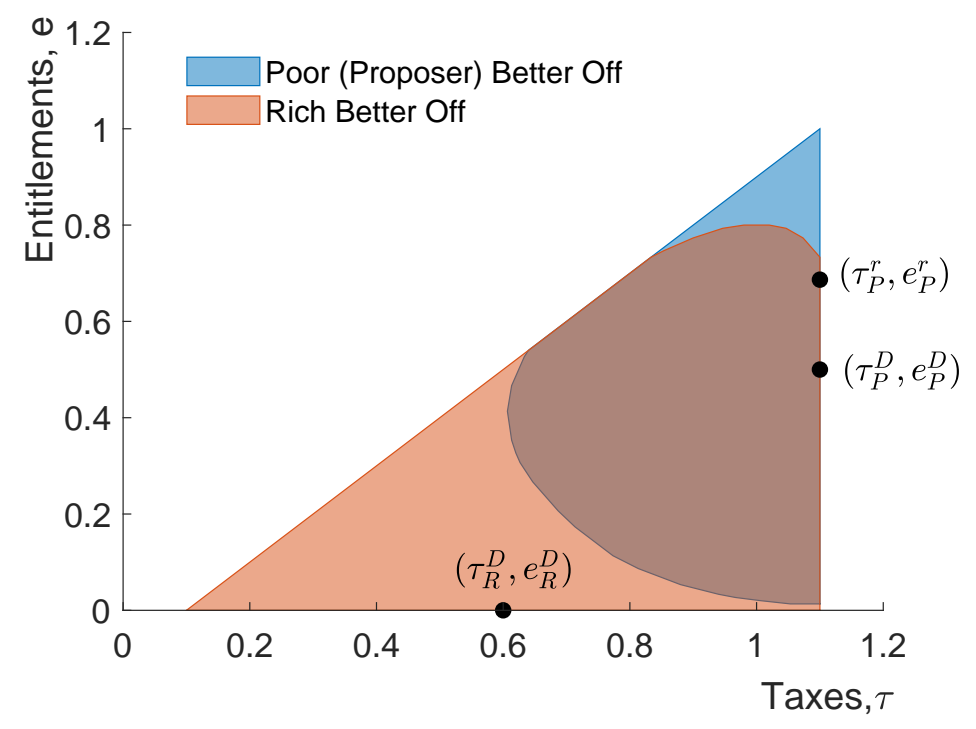

Figure 15: Reform area for benchmark case $(q=0.5)$.

$e_{R}^{D}$, but the $R$ would be willing to introduce budget rules if $\tau_{P}^{D}$ and $e_{P}^{D}$ were proposed instead (as this belongs to the area where the reform is beneficial for both parties). However, and consistently with our results in the two-period model, $P$ would not find it optimal to offer her preferred policies under discretion $s_{P}^{D}$. The proposer would take advantage of her role and offer an alternative policy bundle, denoted by $\left(\tau_{P}^{r}, e_{P}^{r}\right)$ in the plot, making $R$ just indifferent from staying under discretion, while at the same time putting her party at a more advantageous position in the future. Party $P^{\prime}$ 's optimal proposal sets taxes at their maximum feasible level and introduces a more generous entitlement program than under discretion, $e_{P}^{r}>e_{P}^{D}$. While the reform has to be acceptable to both parties, the sequence of play has given the proposer a 'first mover' advantage. By choosing the initial status quo, she can get disproportionate welfare gains. The opposition $R$ is willing to accept this proposal, despite the fact that it implies lower $g$ in the current period, because it induces higher continuation utility: $R$ understands that she will have the ability to tilt policy in her favor once she becomes the proposer, which is very likely under $q=0.5$, and this compensates her for the lower current-period utility.

That parties are willing to agree to the introduction of the budget rules is not a general result. The reform area depends, among other things, on the degree of political persistence. As $q$ risesincreasing the first mover advantage-, the set of policies that generate a Pareto improvement shrink significantly. This is illustrated in the left panel of Figure 16, for $q=0.68$. Because the gains of adopting budget rules is smaller for party $R$ when she is less likely to become a proposer, the proposer must offer an initial status quo exhibiting lower taxes and entitlement generosity in order for the reform to pass (note that now $\tau_{P}^{r}$ and $e_{P}^{r}$ are inside of the set, rather than at the extremes). There may even be cases where the sets become disjoint, as seen on the right panel of the figure for $q=0.88$. In such situations, there is no initial status-quo value that makes both parties better off under rules. In this situation, the proposed reform would never be implemented.

Finally, we want to note that the analysis performed incorporates not only steady state gains, but also the transition from discretion to a new steady state under budget rules. These transition costs are an important consideration to the parties involved in the potential implementation of the reform, and must be taken into consideration when evaluating the merits of such rules. 

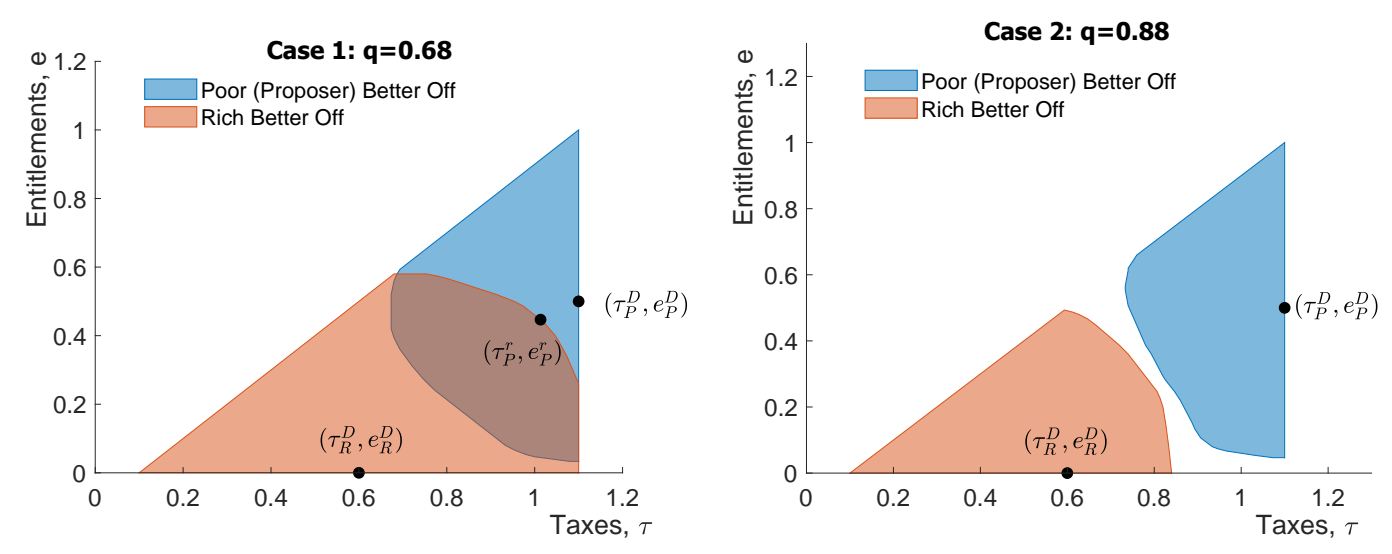

Figure 16: Reform area, alternative values of $q$.

\section{Conclusion}

We described the welfare effects of introducing budget rules determining the tax code and the level of entitlement programs in an environment where risk-averse individuals disagree of redistribution. Quantitatively, we find that rules induce under-provision of public goods, but result in a smoother sequence of private consumption than discretion. Whether they are good for society or not depends critically on political turnover and on the initial conditions of the program (e.g. the initial status quo tax and entitlement program size). When there is frequent alternation between proposers, introducing budget rules generates Pareto improvements. Rules are no better than discretion, on the other hand, when political persistence is large and the initial conditions favor proposers or respondents in a disproportionate way, as they result in less equitable allocations. Finally, we describe conditions under which budget rules would arise in ex-ante bargaining equilibrium.

Our model can be extended in several interesting dimensions. We assumed away the distortionary costs of taxation that may be associated to implementing the equilibrium allocations. If implementing specific allocations were to change the size of the budget, this would plausibly impact the welfare gains of alternative budget rules. We have also assumed that the government was subject to a balanced budget. The only way in which the poor can increase the size of entitlements or the rich can introduce a tax-cut is by sacrificing the provision of public goods, which is the only discretionary tool at their disposal. If the government were able to issue debt, we would expect parties to potentially agree to borrow in order to achieve their desired allocations. However, as Bouton, Lizzeri, and Persico (2020) pointed out, entitlement programs may be a good substitute for debt in these types of models. It would be interesting, thus, to augment our model to consider the possibility of issuing public debt or to accumulate foreign reserves or assets and study whether policymakers would use all these instruments in the political equilibrium.

We have considered a situation where the income level of each agent is fully persistent over time. This makes the preferred fiscal policy by each group starkly different. If agents were subject to idiosyncratic risk, however, entitlement programs would also provide some insurance making it a desirable mandatory program for all agents in society. Other possible extensions involve studying how volatility in the endowment or changes in the degree of income inequality could affect our findings. 


\section{References}

Acemoglu, D., M. Golosov, and A. Tsyvinski (2011). Power fluctuations and political economy. Journal of Economic Theory 146(146), 1009-1041.

Agranov, M., C. Cotton, and C. Tergiman (2020). Persistence of power: Repeated multilateral bargaining with endogenous agenda setting authority. Journal of Public Economics 184, 104126.

Alesina, A. and G. Tabellini (1990, 07). A Positive Theory of Fiscal Deficits and Government Debt. The Review of Economic Studies 57(3), 403-414.

Amador, M., I. Werning, and G.-M. Angeletos (2006). Commitment vs. flexibility. Econometrica 74(2), 365-396.

Anesi, V. (2010). Noncooperative foundations of stable sets in voting games. Games and Economic Behavior 70(2), 488-493.

Anesi, V. and D. J. Seidmann (2013). Bargaining in standing committees with an endogenous default. Review of Economic Studies 82(3), 825-867.

Arellano, C., Y. Bai, and G. Mihalache (2020, January). Monetary Policy and Sovereign Risk in Emerging Economies (NK-Default). Staff Report 592, Federal Reserve Bank of Minneapolis.

Azzimonti, M. (2011, August). Barriers to investment in polarized societies. American Economic Review 101(5), 2182-2204.

Azzimonti, M., M. Battaglini, and S. Coate (2016). The costs and benefits of balanced budget rules: Lessons from a political economy model of fiscal policy. Journal of Public Economics 136(February), 45-61.

Azzimonti, M., L. Karpuska, and G. Mihalache (2020). Bargaining over Mandatory Spending and Entitlements. Technical report.

Baron, D. P. and J. A. Ferejohn (1989). Bargaining in Legislatures. The American Political Science Review 83(4), 1181-1206.

Baron, D. P. and M. C. Herron (2003). A dynamic model of multidimensional collective choice. Computational Models in Political Economy, 13.

Battaglini, M. and S. Coate (2007, March). Inefficiency in legislative policymaking: A dynamic analysis. American Economic Review 97(1), 118-149.

Battaglini, M. and S. Coate (2008, March). A dynamic theory of public spending, taxation, and debt. American Economic Review 98(1), 201-36.

Besley, T. and S. Coate (1997). An Economic Model of Representative Democracy. The Quarterly Journal of Economics 112(1), 85-114.

Bhaskar, V., G. J. Mailath, and S. Morris (2013). A foundation for markov equilibria in sequential games with finite social memory. Review of Economic Studies 80(3), 925-948.

Bouton, L., A. Lizzeri, and N. Persico (2020). The political economy of debt and entitlements. The Review of Economic Studies. 
Bowen, T. R., Y. Chen, and H. Eraslan (2014). Mandatory Versus Discretionary Spending: The Status Quo Effect. American Economic Review 104(10), 2941-74.

Bowen, T. R., Y. Chen, H. Eraslan, and J. Zápal (2017). Efficiency of flexible budgetary institutions. Journal of Economic Theory 167(167), 148-176.

Chatterjee, S. and B. Eyigungor (2012, October). Maturity, Indebtedness, and Default Risk. American Economic Review 102(6), 2674-2699.

Chatterjee, S. and B. Eyigungor (2020). Policy Inertia, Election Uncertainty, and Incumbency Disadvantage of Political Parties. The Review of Economic Studies 87(6), 2600-2638.

Davila, J., J. Eeckhout, and C. Martinelli (2009). Bargaining over public goods. Journal of Public Economic Theory 11(6), 927-945.

Diermeier, D., G. Egorov, and K. Sonin (2017). Political Economy of Redistribution. Econometrica $85(3), 851-870$.

Diermeier, D. and P. Fong (2011). Legislative bargaining with reconsideration. The Quarterly Journal of Economics 126(2), 947-985.

Diermeier, D., C. Prato, and R. Vlaicu (2016). A bargaining model of endogenous procedures. Social Choice and Welfare 47(4), 985-1012.

Duggan, J. and T. Kalandrakis (2012). Dynamic legislative policy making. Journal of Economic Theory 147(5), 1653-1688.

Dziuda, W. and A. Loeper (2016). Dynamic Collective Choice With Endogenous Status Quo. Journal of Political Economy 124.4, 1148-1186.

Dziuda, W. and A. Loeper (2018). Dynamic Pivotal Politics. American Political Science Review 112.3, 580-601.

Eraslan, H., K. Evdokimov, and J. Zápal (2020). Dynamic legislative bargaining. Technical report, Institute of Social and Economic Research, Osaka University.

Eyigungor, B. and S. Chatterjee (2019, January). Incumbency Disadvantage of Political Parties: The Role of Policy Inertia and Prospective Voting. Working Papers 19-7, Federal Reserve Bank of Philadelphia.

Gordon, G. (2019, September). Efficient Computation with Taste Shocks. Working Paper 19-15, Federal Reserve Bank of Richmond.

Grechyna, D. (2017). Mandatory spending, political polarization, and macroeconomic volatility. Political Polarization, and Macroeconomic Volatility (September 27, 2017).

Halac, M. and P. Yared (2014). Fiscal Rules and Discretion Under Persistent Shocks. Econometrica: Journal of the Econometric Society 82(5).

Kalandrakis, A. (2004). A three-player dynamic majoritarian bargaining game. Journal of Economic Theory 116(2), 294-322.

Kalandrakis, A. (2010). Minimum winning coalitions and endogenous status quo. International Journal of Game Theory 39, 617-643. 
Lizzeri, A. and N. Persico (2001, March). The provision of public goods under alternative electoral incentives. American Economic Review 91(1), 225-239.

Mailath, G. J. and L. Samuelson (2006). Repeated Games and Reputations, Volume 84.

Martin, F. (2009, October). A Positive Theory of Government Debt. Review of Economic Dynamics 12(4), 608-631.

Martin, F. (2020). How to Starve the Beast: Fiscal Policy Rules. Federal Reserve Bank of St. Louis Working Paper 2019-026C.

McFadden, D. (1973). Conditional logit analysis of qualitative choice behavior.

Mihalache, G. (2020). Sovereign default resolution through maturity extension. Journal of International Economics, 103326.

Nunnari, S. (2018). Dynamic legislative bargaining with veto power: Theory and experiments. Citeseer.

Osborne, M. J. and A. Slivinski (1996). A model of political competition with citizen-candidates. Quarterly Journal of Economics 111(1), 65-96.

Persson, T. and L. Svensson (1989). Why a stubborn conservative would run a deficit: Policy with time-inconsistent preferences. The Quarterly Journal of Economics 104(2), 325-345.

Persson, T. and G. E. Tabellini (2000). Political Economics: Explaining Economic Policy. MIT Press.

Piguillem, F. and A. Riboni (2011). Dynamic Bargaining over Redistribution in Legislatures. (April), 1-16.

Piguillem, F. and A. Riboni (2020). Fiscal rules as bargaining chips.

Rust, J. (1987, September). Optimal Replacement of GMC Bus Engines: An Empirical Model of Harold Zurcher. Econometrica 55(5), 999-1033.

Sanchez, J. M., M. Dvorkin, E. Yurdagul, and H. Sapriza (2018, June). Sovereign Debt Restructurings. Working Papers 2018-13, Federal Reserve Bank of St. Louis.

Yared, P. (2019, May). Rising government debt: Causes and solutions for a decades-old trend. Journal of Economic Perspectives 33(2), 115-40.

\section{Appendix}

\subsection{Proof to Proposition 1.}

For $\lambda \in(0,1)$, the Lagrangian is given by:

$$
\mathcal{L}=\sum_{t=0}^{\infty} \beta^{t}\left\{\lambda U\left(c_{P, t}, g_{t}\right)+(1-\lambda) U\left(c_{R, t}, g_{t}\right)+\psi_{t}\left[Y-c_{P, t}-c_{R, t}-g_{t}\right]\right\}
$$


The first order and Kuhn-Tucker conditions for this problem are $c_{P, t}, c_{R, t}, g_{t}, \psi_{t} \geq 0$ and

$$
\begin{array}{ll}
{\left[c_{P, t}\right] \quad} & \lambda u^{\prime}\left(c_{P, t}\right)-\psi_{t} \leq 0 \\
& c_{P, t}\left[\lambda u^{\prime}\left(c_{P, t}\right)-\psi_{t}\right]=0 \\
{\left[c_{R, t}\right]} & (1-\lambda) u^{\prime}\left(c_{R, t}\right)-\psi_{t} \leq 0 \\
& c_{R, t}\left[(1-\lambda) u^{\prime}\left(c_{R, t}\right)-\psi_{t}\right]=0 \\
{\left[g_{t}\right]} & u^{\prime}\left(g_{t}\right)-\psi_{t} \leq 0 \\
& g_{t}\left[u^{\prime}\left(g_{t}\right)-\psi_{t}\right]=0 \\
{[R C]} & {\left[Y-c_{P, t}-c_{R, t}-g_{t}\right] \psi_{t}=0}
\end{array}
$$

Since $u($.$) is increasing in its argument, \psi_{t}>0$ and eq. (23) holds with equality. Denote by $h($.$) the inverse of the marginal utility of consumption, h()=.u^{\prime-1}($.$) . By eq. (20) and eq. (22) we$ have that $c_{P, t}=h\left(\frac{1}{\lambda}\right) g_{t}$. By eq. (21) and eq. (22), we have that $c_{R, t}=h\left(\frac{1}{1-\lambda}\right) g_{t}$. By eq. (23) we have that $g_{t}=\frac{\gamma}{\mu(\lambda)}$, where $\mu(\lambda)=1+h\left(\frac{1}{\lambda}\right)+h\left(\frac{1}{1-\lambda}\right)$. Plugging back in the first-order conditions above, we have that $c_{P, t}=\Lambda_{P}(\lambda) Y$ and $c_{R, t}=\Lambda_{R}(\lambda) Y$, where

$$
\Lambda_{P}(\lambda)=\frac{h\left(\frac{1}{\lambda}\right)}{\mu(\lambda)} \quad \text { and } \quad \Lambda_{R}(\lambda)=\frac{h\left(\frac{1}{1-\lambda}\right)}{\mu(\lambda)} .
$$

The effect of $\lambda$ on $\Lambda_{P}(\lambda)$ is determined by

$$
\frac{d \Lambda_{P}(\lambda)}{d \lambda}=Y \frac{\left[-h^{\prime}(x) x^{2}(1+h(y))-h^{\prime}(y) y^{2} h(x)\right]}{\mu^{2}(\lambda)}
$$

where $h^{\prime}(x)=\frac{\partial h}{\partial x}, x=\frac{1}{\lambda}$, and $y=\frac{1}{1-\lambda}$.

Claim $1 h^{\prime}(x)=\frac{1}{u^{\prime \prime}(h(x))} \leq 0$.

Proof. Let $u^{\prime}(x)=g(x)$. Then $h(x)=g^{-1}(x)$. This implies that

$$
h^{\prime}(x)=\left(g^{-1}\right)^{\prime}(x)=\frac{1}{g^{\prime}(h(x))}
$$

where the last equality holds by a property of the inverse function. Moreover, since $g^{\prime}(x)=u^{\prime \prime}(x)$, using the result above we can see that $h^{\prime}(x)=\frac{1}{u^{\prime \prime}(h(x))}$. Concavity of $u$ completes the proof.

Since $h()=.u^{\prime}() \geq$.0 and $g^{\prime}()=.u^{\prime \prime}() \leq$.0 , it is easy to see that $\frac{d \Lambda_{P}(\lambda)}{d \lambda}>0$. Analogously, $\frac{d \Lambda_{R}(\lambda)}{d \lambda}<0$.

For $\lambda=0$, by eq. (21) and eq. (22) we have that $c_{R, t}=g_{t}=\frac{\gamma}{2}$. For $\lambda=1$, by eq. (20) and eq. (22) we have that $c_{P, t}=g_{t}=\frac{\gamma}{2}$. 


\subsection{Proof to Corollary 1.}

The cases where $\lambda=0$ and $\lambda=1$ are shown in Appendix 9.1. Let $\lambda \in(0,1)$. The Lagrangian is given by:

$$
\mathcal{L}=\sum_{t=0}^{\infty} \beta^{t}\left\{(1-\lambda) \ln \left(c_{P, t}\right)+\lambda \ln \left(c_{R, t}\right)+\ln \left(g_{t}\right)+\psi_{t}\left[Y-c_{P, t}-c_{R, t}-g_{t}\right]\right\}
$$

Because his utility function satisfies Inada conditions, allocations satisfy $c_{P, t}, c_{R, t}, g_{t}>0$. The first order and Kuhn-Tucker conditions for this problem are $\psi_{t} \geq 0$ and

$$
\begin{aligned}
{\left[c_{P, t}\right] } & \frac{1-\lambda}{c_{P, t}}-\psi_{t}=0 \\
{\left[c_{R, t}\right] } & \frac{\lambda}{c_{R, t}}-\psi_{t}=0 \\
{\left[g_{t}\right] } & \frac{1}{g_{t}}-\psi_{t}=0 \\
{[R C] } & {\left[Y-c_{P, t}-c_{R, t}-g_{t}\right] \psi_{t}=0 . }
\end{aligned}
$$

From eq. (28), we have that $g_{t}=Y-\bar{x}-c_{A, t}$. By eqs. (25) and (27), we have that $c_{R, t}=$ $(1-\lambda) g_{t}$. By (26) and (27), we have that $c_{P, t}=\lambda g_{t}$. By (28), we have that $g_{t}=\frac{Y}{2}$. Going back to eqs. (25) and (26), we have that $c_{R, t}=\frac{(1-\lambda) Y}{2}$ and $c_{P, t}=\frac{\lambda Y}{2}$.

\subsection{Proof to Proposition 2}

Because taxes and transfers are non-distortionary, the maximization problem is equivalent to one where the government chooses allocations directly. In other words, we can re-write the problem as

$$
V^{D}=\max _{\left\{c_{i}, c_{j}, g\right\}}\left\{u\left(c_{i}\right)+u(g)+\beta\left[q V^{D}+(1-q) W^{D}\right]\right\},
$$

subject to the resource constraint (5) and the bounds on consumption $c_{i, t} \geq \bar{x}$. Moreover, the problem of an incumbent is independent of her type when written in terms of allocations, so $V_{i}^{D}=V^{D}$. Because there is no dynamic state variable, the problem is equivalent to

$$
\max _{\left\{c_{j}, g\right\}}\left\{u\left(Y-c_{j}-g\right)+u(g)\right\}
$$

subject to $c_{j} \geq \bar{x}$. Clearly, it is optimal for an incumbent to set $c_{j}=\bar{x}$. The optimal $g$ equates her private marginal benefit of $g$ to her marginal cost. Taking first order conditions yields the result in the proposition.

\subsection{Proof to Corollary 3}

Let $c^{*}=c_{R}^{*}+c_{P}^{*}$ and $c^{D}=c_{R, i}^{D}+c_{P, i}^{D}$. From Proposition 2, we know that since $\Lambda_{i}(\lambda) \leq \frac{1}{2}$ for $i \in\{R, P\}$, then

$$
c^{*}=\left[\Lambda_{P}(\lambda)+\Lambda_{R}(\lambda)\right] Y \leq \frac{Y}{2} .
$$

From 2, $c^{D}=\frac{Y+\bar{x}}{2}>\frac{Y}{2}$. This implies that $c^{D}>c^{*}$. Using the resource constraint and the previous result, it is easy to see that $g^{*} \geq \frac{Y}{2}$ whereas $g^{D}=\frac{\gamma-\bar{x}}{2}<\frac{Y}{2} \Rightarrow g^{D}<g^{*}$. 


\subsection{Proof to Proposition 3}

Let $u(x)=\ln (x)$. Since endowments and taxes are non-distortionary, we can solve the problem in terms of allocations. This requires a transformation for the state space from status-quo policy pairs $\{\bar{\tau}, \bar{e}\}$ into status-quo consumption levels $\left\{\overline{c_{P}}, \overline{c_{R}}\right\}$. The consumer budget constraints provide a simple linear mapping to do this. Given $\mathbf{s}=\left\{\overline{c_{P}}, \overline{c_{R}}\right\}$, party's $P$ Lagrangian for this problem at $t=2$ is given by:

$$
\mathcal{L}=\ln \left(c_{P, 2}\right)+\ln \left(g_{2}\right)+\lambda\left[Y-c_{P, 2}-c_{R, 2}-g_{2}\right]+\psi\left(\ln \left(c_{R, 2}\right)+\ln \left(g_{2}\right)-\ln \left(\overline{c_{R}}\right)-\ln (\bar{x})\right)
$$

The first-order and Kuhn-Tucker conditions are $c_{P, 2}, c_{R, 2}, g_{2} \geq \bar{x}, \lambda, \psi \geq 0$ and

$$
\begin{aligned}
& {\left[c_{P, 2}\right] \quad \frac{1}{c_{P, 2}}-\lambda \leq 0 .} \\
& \left(c_{P, 2}-\bar{x}\right)\left[\frac{1}{c_{P, 2}}-\lambda\right]=0 . \\
& {\left[c_{R, 2}\right] \quad \frac{\psi}{c_{R, 2}}-\lambda \leq 0 .} \\
& \left(c_{R, 2}-\bar{x}\right)\left[\frac{\psi}{c_{R, 2}}-\lambda\right]=0 . \\
& {\left[g_{2}\right] \quad \frac{1+\psi}{g_{2}}-\lambda \leq 0 \text {. }} \\
& \left(g_{2}-\bar{x}\right)\left[\frac{1+\psi}{g_{2}}-\lambda\right]=0 . \\
& {[R C] \quad\left[Y-c_{P, 2}-c_{R, 2}-g_{2}\right] \geq 0 \text {. }} \\
& \lambda\left[Y-c_{P, 2}-c_{R, 2}-g_{2}\right]=0 . \\
& {[I R C] \quad\left[\ln \left(c_{R, 2}\right)+\ln \left(g_{2}\right)-\ln \left(\overline{c_{R}}\right)-\ln (\bar{x})\right] \geq 0 \text {. }} \\
& \psi\left[\ln \left(c_{R, 2}\right)+\ln \left(g_{2}\right)-\ln \left(\overline{c_{R}}\right)-\ln (\bar{x})\right]=0 .
\end{aligned}
$$

The solution to this system depends on the status quo vector $\mathbf{s}=\left\{\overline{c_{R}}, \overline{c_{P}}\right\}$. Denote the solution by functions $\mathcal{C}_{i, P, 2}(\mathbf{s})$ for private consumption, $\mathcal{G}_{P, 2}(\mathbf{s})$ for public goods, and $\Psi_{P, 2}(\mathbf{s})$ and $\mathcal{E}_{P, 2}(\mathbf{s})$ for policy variables.

First note that $\lambda>0$, since $u($.$) is increasing in its arguments. In addition, since we assume \bar{x}$ is relatively small relative to $Y, \mathcal{C}_{i, P, 2}(\mathbf{s}), \mathcal{G}_{P, 2}(\mathbf{s})>\bar{x}$. We have three cases to consider:

- Case 1: $\psi=0$. By eq. (31) we have that $\mathcal{C}_{R, P, 2}(\mathbf{s})=\bar{x}$. By eq. (30), eq. (32) and eq. (33), we have that $\mathcal{C}_{P, P, 2}(\mathbf{s})=\mathcal{G}_{P, 2}(\mathbf{s})=\frac{\gamma-\bar{x}}{2}$. Using eq. (3) to solve for transfers delivers $\mathcal{E}_{P, 2}(\mathbf{s})=\frac{\Delta-\bar{x}}{2}=e_{P}^{D}$. The expression for $\Psi_{P, 2}(\mathbf{s})$ can be obtained from eq. (2). By eq. (34), this case holds if and only if $\overline{c_{R}}=y_{R}-\bar{\tau}<\frac{Y-\bar{x}}{2}$. In terms of policies, this happens when $\bar{\tau}>\frac{\Delta+\bar{x}}{2}=\tau_{R}^{D}$.

- Case 2: $\psi>0, \mathcal{C}_{R, P, 2}(\mathbf{s})=\bar{x}$ and $\mathcal{C}_{P, P, 2}(\mathbf{s}), \mathcal{G}_{P, 2}(\mathbf{s})>\bar{x}$. By eq. (34) we have that $\mathcal{G}_{P, 2}(\mathbf{s})=$ $\overline{c_{R}}=y_{R}-\bar{\tau}$. By eq. (33), we have that $\mathcal{C}_{P, P, 2}(\mathbf{s})=Y-\bar{x}-\overline{c_{R}}$. From eq. (3), we have that $\mathcal{E}_{P, 2}(\mathbf{s})=\bar{\tau}-\bar{x}$. From eq. (2), $\Psi_{P, 2}(\mathbf{s})=\tau_{P}^{D}$. By eq. (30), eq. (32), eq. (31) and the fact that $\mathcal{C}_{R, P, 2}(\mathbf{s}) \geq \bar{x}$, this case holds if and only if $\frac{\Delta}{2}<\bar{\tau} \leq \tau_{R}^{D}$.

- Case 3: $\psi>0$ and $\mathcal{C}_{i, P, 2}(\mathbf{s}), \mathcal{G}_{P, 2}(\mathbf{s})>\bar{x}$. By eq. (30), eq. (31), eq. (32) and eq. (33), we have that $\mathcal{G}_{P, 2}(\mathbf{s})=\frac{Y}{2}=g^{*}$. By eq. (34), we have that $\mathcal{C}_{R, P, 2}(\mathbf{s})=\frac{2 \overline{\mathcal{C O}_{R}}}{Y}$. From eq. (2), we have that $\Psi_{P, 2}(\mathbf{s})=y_{R}-\frac{2 \overline{x c_{R}}}{Y}=y_{R}-\frac{2 \bar{x}\left(y_{R}-\bar{\tau}\right)}{Y}$. The expression for $\mathcal{E}_{P, 2}(\mathbf{s})$ follows by using eq. (3). By eq. (30), eq. (32) and eq. (31), this case holds if and only if $\bar{\tau}<\frac{\Delta}{2}$. 


\subsection{Proof to Proposition 4}

Party's $R$ Lagrangian for this problem at $t=2$ is given by:

$$
\mathcal{L}=\ln \left(c_{R, 2}\right)+\ln \left(g_{2}\right)+\lambda\left[Y-c_{P, 2}-c_{R, 2}-g_{2}\right]+\psi\left(\ln \left(c_{P, 2}\right)+\ln \left(g_{2}\right)-\ln \left(\overline{c_{P}}\right)-\ln (\bar{x})\right)
$$

The first-order and Kuhn-Tucker conditions party $R$ are $c_{P, 2}, c_{R, 2}, g_{2} \geq \bar{x}, \lambda, \psi \geq 0$ and

$$
\begin{aligned}
& {\left[c_{P, 2}\right] \quad \frac{\psi}{c_{P, 2}}-\lambda \leq 0 .} \\
& \left(c_{P, 2}-\bar{x}\right)\left[\frac{\psi}{c_{P, 2}}-\lambda\right]=0 . \\
& {\left[c_{R, 2}\right] \quad \frac{1}{c_{R, 2}}-\lambda \leq 0 .} \\
& \left(c_{R, 2}-\bar{x}\right)\left[\frac{1}{c_{R, 2}}-\lambda\right]=0 . \\
& {\left[g_{2}\right] \quad \frac{1+\psi}{g_{2}}-\lambda \leq 0} \\
& \left(g_{2}-\bar{x}\right)\left[\frac{1+\psi}{g_{2}}-\lambda\right]=0 . \\
& {[R C] \quad\left[Y-c_{P, 2}-c_{R, 2}-g_{2}\right] \geq 0 \text {. }} \\
& \lambda\left[Y-c_{P, 2}-c_{R, 2}-g_{2}\right]=0 . \\
& {[\text { IRC }] \quad\left[\ln \left(c_{P, 2}\right)+\ln \left(g_{2}\right)-\ln \left(\overline{c_{P}}\right)-\ln (\bar{x})\right] \geq 0 \text {. }} \\
& \psi\left[\ln \left(c_{P, 2}\right)+\ln \left(g_{2}\right)-\ln \left(\overline{c_{P}}\right)-\ln (\bar{x})\right]=0 .
\end{aligned}
$$

First note that $\lambda>0$, since $u($.$) is increasing in its arguments. Also, since we assume \bar{x}$ is relatively small relative to $Y, \mathcal{C}_{i, R, 2}(\mathbf{s}), \mathcal{G}_{R, 2}(\mathbf{s})>\bar{x}$. We have three cases to consider:

- Case 1: $\psi=0$. By eq. (35) we have that $\mathcal{C}_{P, R, 2}(\mathbf{s})=\bar{x}$. By eq. (36), eq. (37) and eq. (38), we have that $\mathcal{C}_{R, R, 2}(\mathbf{s})=\mathcal{G}_{R, 2}(\mathbf{s})=\frac{\gamma-\bar{x}}{2}$. The expressions for $\mathcal{E}_{R, 2}(\mathbf{s})$ and $\Psi_{R, 2}(\mathbf{s})$ can be obtained by replacing allocations into the consumers' budget constraints. By eq. (39), this case holds if and only if $\overline{c_{P}}=y_{P}+\bar{e}<\frac{\gamma-\bar{x}}{2}$. This happens only when $\bar{e}<\frac{\Delta-\bar{x}}{2}=e_{P}^{D}$.

- Case 2: $\psi>0, \mathcal{C}_{P, R, 2}(\mathbf{s})=\bar{x}$ and $\mathcal{C}_{R, R, 2}(\mathbf{s}), \mathcal{G}_{R, 2}(\mathbf{s})>\bar{x}$. By eq. (34) we have that $\mathcal{G}_{R, 2}(\mathbf{s})=$ $\overline{C_{P}}=y_{P}+\bar{e}$. By eq. (33), we have that $\mathcal{C}_{R, R, 2}(\mathbf{s})=Y-\bar{x}-\overline{C_{P}}$. The expressions for $\mathcal{E}_{R, 2}(\mathbf{s})$ and $\Psi_{R, 2}(\mathbf{s})$ can be obtained by replacing allocations into the consumers' budget constraints. By eq. (30), eq. (32), eq. (31) and the fact that $\mathcal{C}_{P, R, 2}(\mathbf{s}) \geq \bar{x}$, this case holds if and only if $\frac{\Delta-\bar{x}}{2}=e_{P}^{D}<\bar{e} \leq \frac{\Delta}{2}$.

- Case 3: $\psi>0$ and $\mathcal{C}_{i, R, 2}(\mathbf{s}), \mathcal{G}_{R, 2}(\mathbf{s})>\bar{x}$. By eq. (30), eq. (31), eq. (32) and eq. (33), we have that $\mathcal{G}_{R, 2}(\mathbf{s})=\frac{Y}{2}=g^{*}$. By eq. (34), we have that $\mathcal{C}_{P, R, 2}(\mathbf{s})=\frac{2 \overline{\mathcal{C l}_{P}}}{Y}$. The expressions for $\mathcal{E}_{R, 2}(\mathbf{s})$ and $\Psi_{R, 2}(\mathbf{s})$ can be obtained by replacing allocations into the consumers' budget constraints. By eq. (30), eq. (32) and eq. (31), this case holds if and only if $\bar{e} \geq \frac{\Delta}{2}$.

\subsection{Proof to Proposition 5}

Since taxes and entitlements are all non-distortionary, we can write the whole problem in terms of allocations. Continuation values in terms of allocations satisfy: 


$$
V_{P}\left(c_{R, 1}\right)=\left\{\begin{array}{lll}
\ln \left(\frac{Y-\bar{x}}{2}\right)+\ln \left(\frac{Y-\bar{x}}{2}\right), & \text { if } & c_{R, 1}<\frac{Y-\bar{x}}{2} \\
\ln \left(Y-\bar{x}-c_{R, 1}\right)+\ln \left(c_{R, 1}\right), & \text { if } & c_{R, 1} \in\left[\frac{Y-\bar{x}}{2}, \frac{Y}{2}\right) \\
\ln \left(\frac{Y}{2}-\frac{2 \bar{x} c_{R, 1}}{Y}\right)+\ln \left(\frac{Y}{2}\right), & \text { if } & c_{R, 1} \geq \frac{Y}{2}
\end{array}\right.
$$

and

$$
W_{P}\left(c_{P, 1}\right)=\left\{\begin{array}{lll}
\ln (\bar{x})+\ln \left(\frac{Y-\bar{x}}{2}\right), & \text { if } & c_{P, 1}<\frac{Y-\bar{x}}{2} . \\
\ln (\bar{x})+\ln \left(c_{P, 1}\right), & \text { if } \quad c_{P, 1} \in\left[\frac{Y-\bar{x}}{2}, \frac{Y}{2}\right) \\
\ln \left(\frac{2 \bar{x} c_{P, 1}}{Y}\right)+\ln \left(\frac{Y}{2}\right), & \text { if } \quad & c_{P, 1} \geq \frac{Y}{2}
\end{array}\right.
$$

Note that the only relevant state for party $P$ when in power is $c_{R, 1}$ and for when out of power is $c_{P, 1}$. Therefore, party's $P$ Lagrangian for this problem at $t=1$ is given by:

$$
\mathcal{L}=\ln \left(c_{P, 1}\right)+\ln \left(g_{1}\right)+\beta\left[q V_{P}\left(c_{R, 1}\right)+(1-q) W_{P}\left(c_{P, 1}\right)\right]+\lambda\left[Y-c_{P, 1}-c_{R, 1}-g_{1}\right]
$$

The first-order and Kuhn-Tucker conditions party $P$ are $c_{P, 1}, c_{R, 1}, g_{1} \geq \bar{x}, \lambda, \psi \geq 0$ and

$$
\begin{aligned}
& {\left[c_{P, 1}\right] \quad \frac{1}{c_{P, 1}}+\beta(1-q) \frac{d W^{P}}{d c_{P, 1}}-\lambda \leq 0 .} \\
& \left(c_{P, 1}-\bar{x}\right)\left[\frac{1}{c_{P, 1}}+\beta(1-q) \frac{d W^{P}}{d c_{P, 1}}-\lambda\right]=0 . \\
& {\left[c_{R, 1}\right] \quad \beta q \frac{d V^{P}}{d c_{R, 1}}-\lambda \leq 0 .} \\
& \left(c_{R, 1}-\bar{x}\right)\left[\beta q \frac{d V^{P}}{d c_{R, 1}}-\lambda\right]=0 . \\
& {\left[g_{1}\right] \quad \frac{1}{g_{1}}-\lambda \leq 0 \text {. }} \\
& \left(g_{1}-\bar{x}\right)\left[\frac{1}{g_{1}}-\lambda\right]=0 . \\
& {[R C] \quad\left[Y-c_{P, 1}-c_{R, 1}-g_{1}\right] \geq 0 \text {. }} \\
& \lambda\left[Y-c_{P, 1}-c_{R, 1}-g_{1}\right]=0 .
\end{aligned}
$$

Again, first note that $\lambda>0$, since $u($.$) is increasing in its arguments. Also, since we assume \bar{x}$ is relatively small relative to $Y, \mathcal{C}_{P, P, 1}, \mathcal{G}_{P, 1}>\bar{x}$. Also, by eq. (41), we have that $\mathcal{C}_{R, P, 1}=\bar{x}$. This

implies that $\frac{d V^{P}\left(c_{R, 1}\right)}{d c_{R, 1}}=0$. By eq. (43), we have that $c_{P, 1}=Y-\bar{x}-g_{1}$ and $\frac{d W^{P}\left(c_{P, 1}\right)}{d c_{P, 1}}=\frac{1}{c_{P, 1}}$. By eq. (40) and eq. (42), we have that $\mathcal{G}_{P, 1}=\frac{\gamma-\bar{x}}{2+\beta(1-q)}=\frac{2}{2+\beta(1-q)} g^{D}$. Back to eq. (43), we have that $\mathcal{C}_{P, P, 1}=(1+\beta(1-q)) \frac{\gamma-\bar{x}}{2+\beta(1-q)}$. Since $\mathcal{C}_{P, P, 1}=y_{P}+\mathcal{E}_{P, 1}$ we have that $\mathcal{E}_{P, 1}=\frac{2 e_{P}^{D}+\beta(1-q) \tau_{D}^{P}}{2+\beta(1-q)}$. Also, since $\mathcal{C}_{R, P, 1}=\bar{x}=y_{R}+\Psi_{P, 1}$, we have that $\Psi_{P, 1}=y_{R}-\bar{x}=\tau_{P}^{D}$.

\subsection{Proof to Proposition 4}

We follow as for the problem of party $P$. Party's $R$ Lagrangian for this problem at $t=1$ is given by:

$$
\mathcal{L}=\ln \left(c_{R, 1}\right)+\ln \left(g_{1}\right)+\beta\left[q V_{R}\left(c_{P, 1}\right)+(1-q) W_{R}\left(c_{R, 1}\right)\right]+\lambda\left[Y-c_{P, 1}-c_{R, 1}-g_{1}\right]
$$


The first-order and Kuhn-Tucker conditions party $R$ are $c_{P, 1}, c_{R, 1}, g_{1} \geq \bar{x}, \lambda, \psi \geq 0$ and

$$
\begin{aligned}
& {\left[c_{R, 1}\right] \quad \frac{1}{c_{R, 1}}+\beta(1-q) \frac{d W^{R}}{d c_{R, 1}}-\lambda \leq 0 .} \\
& \left(c_{R, 1}-\bar{x}\right)\left[\frac{1}{c_{R, 1}}+\beta(1-q) \frac{d W^{R}}{d c_{R, 1}}-\lambda\right]=0 . \\
& {\left[c_{P, 1}\right] \quad \beta q \frac{d V^{R}}{d c_{P, 1}}-\lambda \leq 0 .} \\
& \left(c_{P, 1}-\bar{x}\right)\left[\beta q \frac{d V^{R}}{d c_{P, 1}}-\lambda\right]=0 . \\
& {\left[g_{1}\right] \quad \frac{1}{g_{1}}-\lambda \leq 0 .} \\
& \quad\left(g_{1}-\bar{x}\right)\left[\frac{1}{g_{1}}-\lambda\right]=0 . \\
& {[R C] \quad\left[Y-c_{P, 1}-c_{R, 1}-g_{1}\right] \geq 0 .} \\
& \lambda\left[Y-c_{P, 1}-c_{R, 1}-g_{1}\right]=0 .
\end{aligned}
$$

Again, first note that $\lambda>0$, since $u($.$) is increasing in its arguments. Also, since we assume \bar{x}$ is relatively small relative to $Y, \mathcal{C}_{R, R, 1}, \mathcal{G}_{R, 1}>\bar{x}$. Also, by eq. (45), we have that $\mathcal{C}_{P, R, 1}=\bar{x}$. This implies that $\frac{d V^{R}\left(c_{P, 1}\right)}{d c_{P, 1}}=0$. By eq. (43), we have that $c_{R, 1}=Y-\bar{x}-g_{1}$ and $\frac{d W^{R}\left(c_{R, 1}\right)}{d c_{R, 1}}=\frac{1}{c_{R, 1}}$. By eq. (44) and eq. (46), we have that $\mathcal{G}_{R, 1}=\frac{\gamma-\bar{x}}{2+\beta(1-q)}=\frac{2}{2+\beta(1-q)} g^{D}$, as in party's $P$ problem. Back to eq. (43), we have that $\mathcal{C}_{R, R, 1}=(1+\beta(1-q)) \frac{\gamma-\bar{x}}{2+\beta(1-q)}$. Since $\mathcal{C}_{R, R, 1}=y_{R}-\Psi_{1}$ we have that $\Psi_{1}=\frac{y_{R}+(1+\beta(1-q)) e_{R}^{D}}{2+\beta(1-q)}$. Also, since $\mathcal{C}_{P, R, 1}=\bar{x}=y_{P}+\mathcal{E}_{R, 1}$, we have that $\mathcal{E}_{R, 1}=\bar{x}-y_{P}=e_{R}^{D}$.

\subsection{Proof to Lemma 1}

Let $P$ be the proposer in the first period, since $q=0, R$ is the proposer in $t=2$. Under discretion, the lifetime welfare of $R$ and $P$ are given, respectively, by

$$
\begin{aligned}
& U_{P}^{D}=(2+\beta) \ln \left(c_{P, P}^{D}\right)+\beta \ln (\bar{x}) \\
& U_{R}^{D}=\ln (\bar{x})+(1+2 \beta) \ln \left(c_{R, R}^{D}\right)
\end{aligned}
$$

where $c_{i, i}^{D}=\frac{Y-\bar{x}}{2}$, as shown in previous results. To find lifetime welfare under budget rules, first use Proposition 5, evaluated at $q=0$, to find first period allocations.

$$
\mathcal{C}_{P, P, 1}=\frac{2(1+\beta)}{2+\beta} c_{P, P}^{D} \quad \mathcal{G}_{P, 1}=\frac{2}{2+\beta} c_{P, P}^{D} \quad \text { and } \quad \mathcal{C}_{R, P, 1}=\bar{x}
$$

Under the assumption that $\bar{x} \rightarrow 0$, the relevant state variable for proposer $R$ at the outset of the second period is given by $c_{P, 1}=\mathcal{C}_{P, P, 1} \geq \frac{Y}{2}$. Hence, second period allocations satisfy

$$
\mathcal{C}_{P, R, 2}=\frac{2 \bar{x} c_{P, 1}}{Y} \quad \mathcal{G}_{R, 2}=\frac{Y}{2} \quad \text { and } \quad \mathcal{C}_{R, R, 2}=\frac{Y}{2}-\frac{2 \bar{x} c_{P, 1}}{Y} .
$$

The lifetime welfare of $R$, under budget rules, is thus

$$
U_{R}^{B R}=\ln (\bar{x})+\ln \left(\frac{2}{2+\beta} c_{P, P}^{D}\right)+\beta\left\{\ln \left(\frac{Y}{2}\right)+\ln \left(\frac{Y}{2}-\frac{2 \bar{x} c_{P, 1}}{Y}\right)\right\}
$$


Noting that $\frac{Y}{2}-\frac{2 \bar{x} c_{P, 1}}{Y}=\frac{Y}{2}\left[1-\frac{4 \bar{x} c_{P, 1}}{Y^{2}}\right]$, and simplifying, the welfare gain obtained by $R$ from imposing budget rules is given by

$$
U_{R}^{B R}-U_{R}^{D}=\ln \left(\frac{2}{2+\beta}\right)+2 \beta\left[\ln \left(\frac{Y}{2}\right)-\ln \left(c_{R, R}^{D}\right)\right]+\beta \ln \left(1-\frac{4 \bar{x} c_{P, 1}}{Y^{2}}\right) .
$$

The values inside the first and last terms are smaller than 1 , so their natural logarithm is negative. Taking limits when $\bar{x} \rightarrow 0$, the second and third terms go to 0 since $c_{R, R}^{D}=\frac{Y-\bar{x}}{2}$. As a result, $R$ 's lifetime welfare is lower under budget rules than under discretion. Numerically, it is easy to see that this holds for $\bar{x}>0$.

\section{Numerical Implementation}

Because the lower bounds for rich and poor agents are the same, inspection of the maximization problem above reveals that the model, when written in terms of allocations, is completely symmetric. This means that the allocations proposed for the incumbent and the opposition are independent of the type of proposer. In other words, that the type- $R$ proposer and the type- $P$ proposer, facing the same state variables, would choose the same level of consumption for themselves if given proposal power. This symmetry can be exploited to further simplify the computational algorithm. With a slight abuse of notation, let $V$ and $W$ denote the value functions for the proposer and for the party out of power, respectively, while $\mathcal{C}, \mathcal{C}_{-}$, and $\mathcal{G}$ are the policy functions for proposer's consumption, opposition's private consumption, and the provision of public goods, respectively. The problem of the proposer, facing state $\left(\bar{c}_{,} \bar{c}_{-}\right)$for her consumption and that of the opposition, reduces to

$$
\begin{aligned}
\max _{c, c_{-}, g} u(c)+u(g)+\beta\left\{q V\left(c, c_{-}\right)+(1-q) W\left(c_{-}, c\right)\right\} \\
\text { s.t. } u\left(c_{-}\right)+u(g)+\beta\left\{(1-q) V\left(c_{-}, c\right)+q W\left(c, c_{-}\right)\right\} \\
\geq u\left(\bar{c}_{-}\right)+u(\bar{x})+\beta\left\{(1-q) V\left(\bar{c}_{-}, \bar{c}\right)+q W\left(\bar{c}, \bar{c}_{-}\right)\right\} \\
\quad c_{,} c_{-}, \geq \bar{x}, \quad c+c_{-}+g \leq Y
\end{aligned}
$$

Note that the states need to be changed in $W$, because if the current incumbent loses power next period, she will be entitled to (opposition) consumption $c_{-}$.

The welfare function of the group that is not a proposer is given by:

$$
\begin{aligned}
W\left(\bar{c}, \bar{c}_{-}\right)= & u\left[\mathcal{C}_{-}\left(\bar{c}, \bar{c}_{-}\right)\right]+u\left[\mathcal{G}\left(\bar{c}_{c}, \bar{c}_{-}\right)\right] \\
& +\beta(1-q) V\left[\mathcal{C}_{-}\left(\bar{c}_{,}, \bar{c}_{-}\right), \mathcal{C}\left(\bar{c}, \bar{c}_{-}\right)\right] \\
& +\beta q W\left[\mathcal{C}\left(\bar{c}_{,} \bar{c}_{-}\right), \mathcal{C}_{-}\left(\bar{c}_{,}, \bar{c}_{-}\right)\right]
\end{aligned}
$$

whereas $V$ is obtained by replacing $c=\mathcal{C}\left(\bar{c}_{,} \bar{c}_{-}\right)$and $g=\mathcal{G}\left(\bar{c}, \bar{c}_{-}\right)$in the right hand side of equation (48). As a result of this transformation, we only need to compute five equilibrium objects: two value functions, $V$ and $W$, and three policy functions $\mathcal{C}, \mathcal{C}_{-}$, and $\mathcal{G}$. This is in contrast with the original problem which involved solving for thirteen policy rules (e.g., 4 functions for fiscal policy, 4 value functions, and 5 allocation functions). 


\subsection{Triangular Grid}

We solve the model "on the grid," so that both the status quo and chosen allocations must lie on our grid, using taste shocks methods to be detailed shortly. We construct a triangular grid so that all points respect resource feasibility.

We fix a grid for the level of private consumption, $n$ elements equally spaced over $\left[\bar{x}_{c}, Y-\bar{x}_{c}-\bar{x}_{g}\right]$. Then, we consider the Cartesian product of two such vectors, discarding pairs that would violate $g=Y-c_{i}-c_{j} \geq \bar{x}_{g}$. We are left with $\tilde{n}=(n+1) n / 2$ grid points. Denote, for future reference, the set of all grid elements by $\mathrm{S}$.

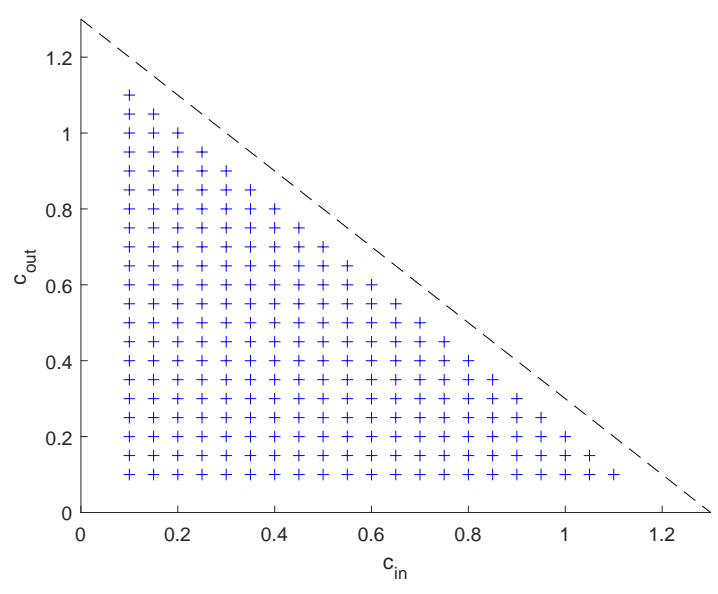

(a) Example: $n=21, \tilde{n}=231$

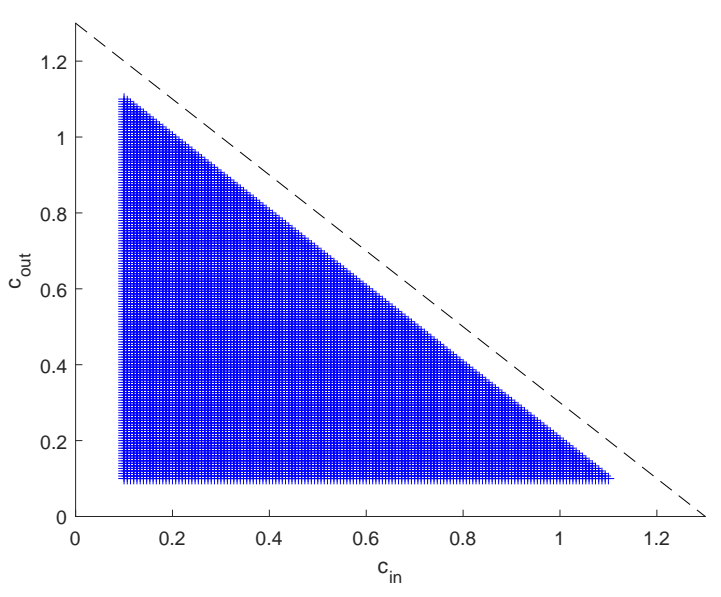

(b) Actual: $n=151, \tilde{n}=11,476$

Figure 17: Triangular Grids

In Figure 17 we plot two such grids, first an example for illustration in Figure 17a, for $n=21$, and the actual grid used in the computation, in Figure 17b, with $n=151$ for a total of 11,476 possible choices.

\subsection{Computation with Taste Shocks}

We perturb the proposer's problem by augmenting it with choice-specific taste shocks, distributed Gumbel (Extreme Value Type I), following Gordon $(2019)^{15}$, as commonly employed with discrete choice methods, e.g. Rust (1987). To simplify notation, let the status quo be given by $\bar{s}=\left\langle\bar{c}_{i}, \bar{c}_{j}\right\rangle$ and any potential choice denoted by $s=\left\langle c_{i}, c_{j}, g\right\rangle$ and its associated proposer turn-over counterpart $f(s)=\left\langle c_{j}, c_{i}, g\right\rangle$.

Define the acceptance set as

$$
R(\bar{s})=\left\{s \in \mathbb{S} \mid u\left(c_{j}, g\right)+\beta[(1-q) V(s)+q W(f(s))] \geq K(\bar{s})\right\} .
$$

We write the value to the proposer from proposing $s^{\prime}$, net of taste shocks, as

$$
\mathcal{J}(\bar{s}, s)= \begin{cases}u\left(c_{i}, g\right)+\beta\{q V(s)+(1-q) W(f(s))\}, & \text { if } s \in R(\bar{s}) \\ -\infty, & \text { otherwise }\end{cases}
$$

\footnotetext{
${ }^{15}$ Related, recent applications to fiscal policy and sovereign default include Sanchez et al. (2018), Mihalache (2020), and Arellano et al. (2020).
} 
and record the greatest value over $s$ by

$$
\overline{\mathcal{J}}(\bar{s})=\max _{s \in \mathrm{S}} \mathcal{J}(\bar{s}, s)
$$

The value to the proposer, given realized iid taste shocks $\left\{\varepsilon_{s}\right\}_{s}$ is

$$
\mathcal{V}\left(\bar{s},\left\{\varepsilon_{s}\right\}_{s}\right)=\max _{s \in \mathrm{S}}\left\{\mathcal{J}(\bar{s}, s)+\rho \varepsilon_{s}\right\}
$$

Following the standard proofs for discrete choice methods, e.g. McFadden (1973), it can be shown that ex-ante, before taste shocks are realized, the probability of choosing a particular option $\hat{s}$ is given by

$$
\operatorname{Pr}(s=\hat{s} \mid \bar{s})=\frac{\exp [\mathcal{J}(\bar{s}, \hat{s}) / \rho]}{\sum_{z} \exp [\mathcal{J}(\bar{s}, z) / \rho]}=\frac{\exp [(\mathcal{J}(\bar{s}, \hat{s})-\overline{\mathcal{J}}(\bar{s})) / \rho]}{\sum_{z} \exp [(\mathcal{J}(\bar{s}, z)-\overline{\mathcal{J}}(\bar{s})) / \rho]}
$$

and the expected value to the proposer, before observing the taste shocks, is

$$
V(\bar{s})=\mathbb{E}_{\left\{\varepsilon_{s}\right\}_{s}}\left\{\mathcal{V}\left(\bar{s},\left\{\varepsilon_{s}\right\}_{s}\right)\right\}=\overline{\mathcal{J}}(\bar{s})+\rho \log \left\{\sum_{z} \exp [(\mathcal{J}(\bar{s}, z)-\overline{\mathcal{J}}(\bar{s})) / \rho]\right\}
$$

while the value of the agent receiving the proposal is

$$
W(\bar{s})=\sum_{z}\left\{\operatorname{Pr}(s=z \mid \bar{s})\left[u\left(c_{j}, g\right)+\beta((1-q) V(z)+q W(f(z)))\right]\right\} .
$$

We remark briefly on key properties of the choice probabilities and of the solution. First, the probability of choosing $s$ is strictly increasing in the value net of taste shocks for $s, \mathcal{J}(\bar{s}, s)$, so that better options are picked with higher probability. Second, given our use of the acceptance set, all $s$ that would not be accepted are proposed to probability zero. Third, the mean level of the Gumbel tastes shocks is non-zero, yet this does not alter choice probabilities: what matters for the likelihood of choosing $s$ over e.g. $z$ is the difference between $\varepsilon_{s}$ and $\varepsilon_{z}$, which is Logistic $(0,1)$, as well as values net of taste shocks. Finally, the parameter $\rho$ scales the importance of the taste shocks for the proposal decision. If we take value $\rho \rightarrow 0$, tastes shocks no longer play a role and the underlying best option is picked with probability 1. In turn, for arbitrarily high $\rho$ values, all members of the acceptance set would be proposed with equal probability. 